\title{
Gene regulation of Sclerotinia sclerotiorum during infection of Glycine max: on the road to pathogenesis
}

\author{
Nathaniel M. Westrick ${ }^{\dagger}$, Ashish Ranjan ${ }^{\dagger}$, Sachin Jain, Craig R. Grau, Damon L. Smith and Mehdi Kabbage ${ }^{*}$ (D)
}

\begin{abstract}
Background: Sclerotinia sclerotiorum is a broad-host range necrotrophic pathogen which is the causative agent of Sclerotinia stem rot (SSR), and a major disease of soybean (Glycine max). A time course transcriptomic analysis was performed in both compatible and incompatible soybean lines to identify pathogenicity and developmental factors utilized by $S$. sclerotiorum to achieve pathogenic success.
\end{abstract}

Results: A comparison of genes expressed during early infection identified the potential importance of toxin efflux and nitrogen metabolism during the early stages of disease establishment. The later stages of infection were characterized by an apparent shift to survival structure formation. Analysis of genes highly upregulated in-planta revealed a temporal regulation of hydrolytic and detoxification enzymes, putative secreted effectors, and secondary metabolite synthesis genes. Redox regulation also appears to play a key role during the course of infection, as suggested by the high expression of genes involved in reactive oxygen species production and scavenging. Finally, distinct differences in early gene expression were noted based on the comparison of S. sclerotiorum infection of resistant and susceptible soybean lines.

Conclusions: Although many potential virulence factors have been noted in the S. sclerotiorum pathosystem, this study serves to highlight soybean specific processes most likely to be critical in successful infection. Functional studies of genes identified in this work are needed to confirm their importance to disease development, and may constitute valuable targets of RNAi approaches to improve resistance to SSR.

Keywords: Sclerotinia sclerotiorum, Glycine max, Transcriptomics, White Mold, Sclerotinia stem rot, Effectors, Hydrolytic enzymes, Resistance, Oxalic acid, Reactive oxygen species

\section{Background}

Sclerotinia sclerotiorum, the causative agent of Sclerotinia stem rot (SSR) or white mold, is a broad host range necrotrophic fungus that infects soybean (Glycine max) as well as more than 400 other species of plants worldwide [1]. With conducive environmental conditions SSR can be a devastating disease, and from 2010 to 2014 caused an estimated yield loss in the northern United States and Ontario of over 100 million bushels [2]. Along with yield losses, SSR affects seed quality by reducing protein and oil contents [3].

\footnotetext{
* Correspondence: kabbage@wisc.edu

${ }^{\dagger}$ Nathaniel M. Westrick and Ashish Ranjan contributed equally to this work. Department of Plant Pathology, University of Wisconsin-Madison, Madison,
} WI, USA

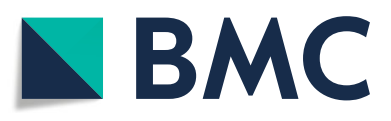

(c) The Author(s). 2019 Open Access This article is distributed under the terms of the Creative Commons Attribution 4.0 International License (http://creativecommons.org/licenses/by/4.0/), which permits unrestricted use, distribution, and reproduction in any medium, provided you give appropriate credit to the original author(s) and the source, provide a link to the Creative Commons license, and indicate if changes were made. The Creative Commons Public Domain Dedication waiver (http://creativecommons.org/publicdomain/zero/1.0/) applies to the data made available in this article, unless otherwise stated. during seasonal crop infection cycles are sclerotia $[4,5]$. Sclerotia are melanized hyphal aggregates that serve as a winter survival structure for the pathogen. These structures can undergo either myceliogenic germination, through the production of vegetative hyphae, or carpogenic germination, through the production of apothecia, the latter of which accounts for most soybean infections [6]. In the case of carpogenic germination, apothecia in the soil release millions of airborne ascospores which initially colonize the petals of soybean blossoms, before travelling through green tissue to the main stem of the plant. This journey through distinct regions of the host is important to note as the metabolic, virulence, and defense requirements of $S$. sclerotiorum may shift in response to the challenges associated with colonizing 
specific tissue types, such as differing levels of glucose [7], $\mathrm{pH}[8]$, and oxidative stress [9].

While several factors implicated in S. sclerotiorum pathogenicity have been characterized (Oxalic acid [10-14], secreted effectors [15-18], cell wall degrading (CWD) enzymes [19-21]), bioinformatic approaches have identified additional putative secreted proteins in S. sclerotiorum that may serve as virulence factors. Guyon et al [22] identified 78 effector candidates through the analysis of protein domains and motifs, signatures of positive selection, recent gene duplication, and sequences unique to $S$. sclerotiorum. Of these candidates, a subset were analyzed during penetration and colonization of Arabidopsis thaliana, and showed distinct patterns of expression, likely correlating with their diverse roles in infection. A comparative analysis of the genomes of S. sclerotiorum and its close relative Botrytis cinerea provided insight into their putative secretomes, but also highlighted many of the numerous hydrolytic, detoxifying, and secondary metabolite synthesizing enzymes that $S$. sclerotiorum may use during infection [23].

Although these studies have borne fruit through the identification and characterization of a number of potential virulence determinants $[15,18]$, in planta transcriptomic studies of S. sclerotiorum are pivotal to understanding the fungal pathogenicity determinants most important for a particular host and stage of infection. Previous studies attempting this in Brassica napus [24] and Phaseolus vulgaris [25] provide useful insight into the regulation of these determinants. The expression of a gene (Ssoah1) coding for an oxaloacetate acetylhydrolase, an enzyme essential in oxalic acid production, and likely the most well-studied virulence factor of $S$. sclerotiorum, was found to be similarly upregulated over the course of infection in both studies. Conversely, the expression and profiles of pectinolytic cell wall degrading enzymes (CWDEs) which are critical in fungal necrotrophy, such as polygalacturonases (PGs) [19], were differentially regulated between these two hosts. As a broad host range pathogen, S. sclerotiorum is capable of adapting to different hosts [26], and the characterization of host specific factors in any given crop system is essential to improve and exploit mechanisms of resistance.

Although integrated management strategies for the control of SSR in soybean are common, a historical limitation to disease control has been a lack of cultivars showing strong physiological resistance [27]. This is complicated by a polygenic resistance composed of both physiological mechanisms of resistance and structural disease avoidance traits (i.e. height, lodging, canopy closure, etc.) which might prove inconsistent with variable environmental and field conditions [28]. Recently, attempts to classify cultivars demonstrating physiological resistance using greenhouse inoculations [27] and a panel of S. sclerotiorum isolates for improved SSR screening [29] have identified selections showing promising resistance. In this study, we capitalize on this selection work to compare transcriptional differences between a successful/compatible S. sclerotiorum infection in a susceptible soybean line and one encountering localized resistance after the onset of infection.

To observe the changes in gene expression of $S$. sclerotiorum over the course of plant colonization, this study has three primary objectives: (1) identify differentially expressed genes over the course of infection in a susceptible soybean line; (2) compare gene expression in S. sclerotiorum in planta and under culture conditions to identify factors important in the $S$. sclerotiorum-soybean pathosystem; and (3) evaluate the differences in gene regulation during SSR infection on susceptible and resistant soybean lines.

\section{Results}

\section{Disease development in susceptible and resistant soybean lines}

S. sclerotiorum pathogenic development was monitored in two recombinant inbred lines (RIL) of soybean showing contrasting levels of susceptibility. The resistant 91-145 (R) and the susceptible 91-44 (S) were the result of crossing between W04-1002 (P1), a SSR resistant parental line, and LN89-5717 (PI 5745542), a parental line susceptible to SSR but demonstrating other desirable traits [27]. Plants were inoculated using the cut petiole method and infection progression was monitored for seven days. SSR symptoms, observed as typical brown lesions surrounding the point of infection, began to appear $48 \mathrm{~h}$ post-inoculation (hpi). At $96 \mathrm{hpi}$ lesions were visible on the main stem of the $\mathrm{S}$ line, while disease progress had slowed substantially and restricted lesions with a red coloration were observed on the node of the $\mathrm{R}$ line (Fig. 1). By day 7 the susceptible soybeans showed extensive lesions along the main stem and began to wilt, whereas the resistant line had largely resisted fungal colonization into the main stem, accompanied by a more prominent red coloration at the infected node of the main stem. The red stem phenotype developed in $90 \%$ of the R plants tested (9 out of 10), while none of the $S$ plants showed this phenotype. The red stem appears to be indicative of a specific resistance response by the $R$ line to inhibit $S$. sclerotiorum pathogenesis and is correlated with the production of antimicrobial compounds affecting fungal growth [30].

\section{RNA Seq analysis of S. sclerotiorum during infection}

Global gene expression changes in S. sclerotiorum were determined following inoculations of the $\mathrm{S}$ and $\mathrm{R}$ lines. We sequenced the mRNA of twenty-four samples, consisting of three independent biological replicates of culture controls and infected soybean tissue at 24, 48, 


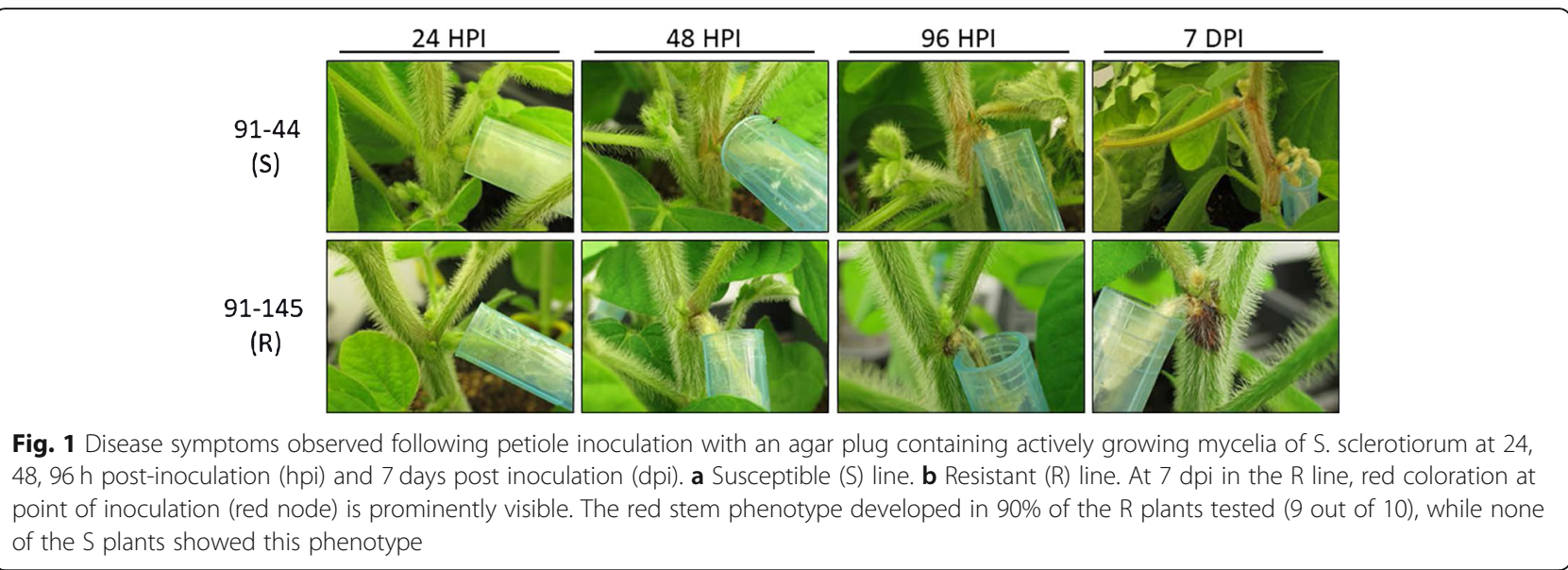

and 96 hpi. A total of 64.9-89.7 million raw reads were generated in each time point of the study, with 3.5 to $27 \%$ mapping to the genome of S. sclerotiorum and 68.9 to $92.8 \%$ mapping to the genome of Glycine max. On average, $96.3 \%$ of the total sequenced reads from the culture controls mapped uniquely to $S$. sclerotiorum strain 1980 genome. All reads that failed to map to either the host or pathogen genome were excluded from the analysis.

Of the reads sequenced from the $\mathrm{S}$ line, approximately 4.4, 4.0, and $27 \%$ mapped to the S. sclerotiorum genome at 24,48 and $96 \mathrm{hpi}$, respectively. In the R line, approximately $3.5,3.8$, and $7.8 \%$ of the reads mapped to the $S$. sclerotiorum genome at 24, 48 and $96 \mathrm{hpi}$, respectively (Table 1). At 96 hpi the percentage of reads mapping to the fungal genome in the S line $(27 \%)$ was significantly higher than those in the $\mathrm{R}$ line (8\%), in accordance with the extent of tissue colonization on the stems of both lines following $S$. sclerotiorum challenge.

\section{Validation of RNA-Seq data using real-time quantitative PCR (RTq-PCR)}

To validate the accuracy of the RNA-Seq data, five previously characterized and three uncharacterized genes showing distinct expression patterns during infection of the $\mathrm{S}$ line were quantified using a SYBR Green based
RT-qPCR. Primers were either designed or culled from the literature (Additional file 1: Table S1). The five previously characterized genes were Sspg5 (Sscle02g018820), Ssv263 (Sscle03g028510), Ssp1 (Sscle10g079320), Sscvnh (Sscle04g 038020), and Ssitl (Sscle08g068500). The three uncharacterized genes were a putative cytochrome p450 monooxygenase (Sscle15g106500), a putative laccase (Sscle03g023030), and a putative serine protease (Sscle05g041810). The expression patterns for each gene, as compared to culture, were similar between RNA-Seq and RT-qPCR, with Ssitl and Sscle05g 041810 showing the greatest variance, but with similar trends between the two methods (Fig. 2). The expression level of Ssoah1 (Sscle10g075560), which was not differentially regulated at any timepoint of infection, was also consistent between the two methods (data not shown). Thus, these results indicate a close correlation between our RT-qPCR and RNAseq data.

\section{S. sclerotiorum gene regulation over the course of a compatible interact}

To examine changes in S. sclerotiorum's transcriptome during pathogenic development in soybean, a differential expression analysis was performed between early and late infection in the $\mathrm{S}$ line. For the purpose of this analysis, "early infection" was defined as the average expression between 24 and $48 \mathrm{hpi}$, and "late infection"

Table 1 Summary of the sequencing metrics of the RNA-seq

\begin{tabular}{lllll}
\hline & Time points (hours) & Total reads & Mapping to S. sclerotiorum & Mapping to Glycine max \\
\hline \multirow{3}{*}{ Susceptible line (Sus) } & Control & $48,381,862$ & $46,655,332(96.3 \%)$ & $0(0.0 \%)$ \\
& $24 \mathrm{hpi}$ & $81,259,978$ & $3,607,921(4.4 \%)$ & $74,457,988(91.6 \%)$ \\
& $48 \mathrm{hpi}$ & $74,344,340$ & $2,941,195(4.0 \%)$ & $68,265,965(91.8 \%)$ \\
Resistant line (Res) & $96 \mathrm{hpi}$ & $69,266,099$ & $18,712,374(27.0 \%)$ & $47,765,044(68.9 \%)$ \\
& $24 \mathrm{hpi}$ & $64,923,300$ & $2,286,347(3.5 \%)$ & $60,261,793(92.8 \%)$ \\
& $48 \mathrm{hpi}$ & $67,520,185$ & $2,513,457(3.8 \%)$ & $62,099,244(91.9 \%)$ \\
& $96 \mathrm{hpi}$ & $72,951,207$ & $5691,551(7.8 \%)$ & $64,399,890(88.2 \%)$ \\
\hline
\end{tabular}




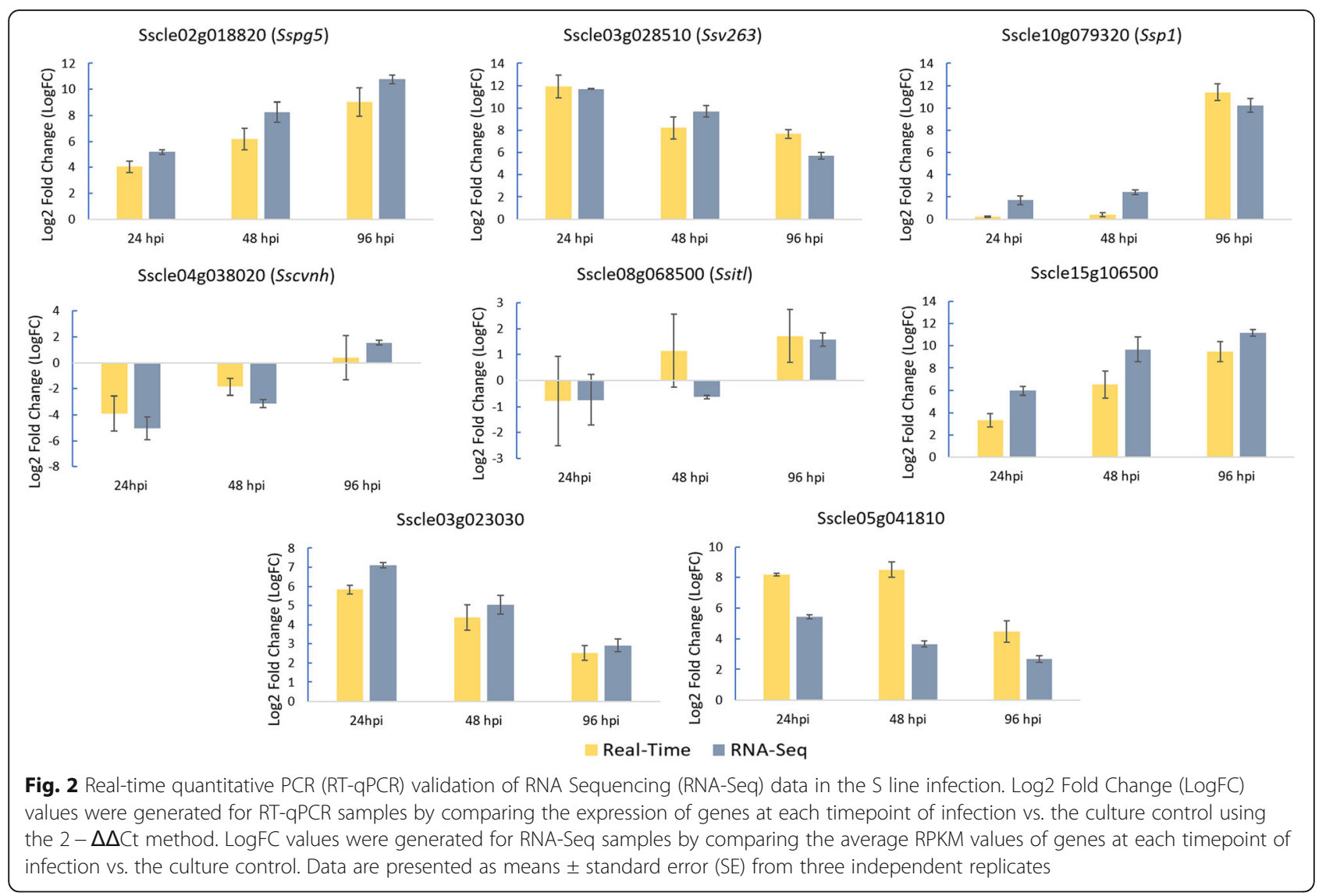

was defined as $96 \mathrm{hpi}$. These assignments were made because of the phenotypic differences between these timepoints (i.e. 24 and $48 \mathrm{hpi}=$ restricted to inoculated petiole, $96 \mathrm{hpi}=$ colonization of the main stem), but also due to a clear regulatory shift in gene expression between these stages of infection (Fig. 3). Differentially expressed genes (DEG's) (False discovery rate (FDR) $<0.05$; Average Reads Per Kilobase of transcript, per Million mapped reads $(\mathrm{RPKM})>1$; and $\log _{2}$ fold change $(\operatorname{logFC}) \geq 1$ or $\left.\leq-1\right)$ were generated and categorized using BlastGo annotation and their predicted role in the infection cycle.

Six hundred fifty-five DEGs were identified over the course of the S line infection, with $76.1 \%$ (431/566) showing up-regulation late in infection (LATE) and 23.9\% (135/566) showing the reverse trend with higher expression early in infection (EARLY) (Additional file 2: Table S2). A functional distribution characterization of both LATE and EARLY genes was performed using the functional distribution tool within the FunCat database (FunCatDb) and S. sclerotiorum's annotated proteins (p3_r20263_Scl_scler) [31]. When functional categories were filtered to reflect only groups that were significantly enriched (Bonferroni correction $<0.05$ ), a wide deviation was apparent. Of the significantly enriched LATE gene categories, most were related to metabolism (27.8\%), degradation $(16.7 \%)$, or catabolism $(11.1 \%)$, all processes important in necrotrophic pathogens for colonization, degradation, and detoxification during infection. Similarly, several gene categories related to virulence and disease (16.7\%) were upregulated late in infection (Fig. 4a; Additional file 3: Table S3A). Unlike the LATE genes, a majority of the categories applied to EARLY genes (66.7\%) and majority of the total EARLY genes categorized (51.6\%) were related to transport. (Fig. 4b; Additional file 3: Table S3B). While it's difficult to infer the exact function of these transporters during soybean infection, it's well established that fungi utilize an array of membrane bound transporters to facilitate the efflux of fungicidal toxins [32]. We also observed differences in the specific categories of transporters that were differentially expressed (Additional file 4: Figure S1; Additional file 2: Table S2). Although major facilitator superfamily (MFS) transporters involved in sugar transport (87.5\%) were upregulated largely late in infection, MFS transporters involved in drug resistance and efflux (61.5\%) and ABC Transporters (66.6\%) were more highly expressed during early stages of infection. This suggests that S. sclerotiorum may prioritize the expulsion of antifungal toxins early in infection, but shifts focus to the transport of carbohydrates at a later stage when sugars have been released from the hosts cell walls.

Broad gene categorizations are often helpful in interpreting large transcriptomic data sets, but the important 


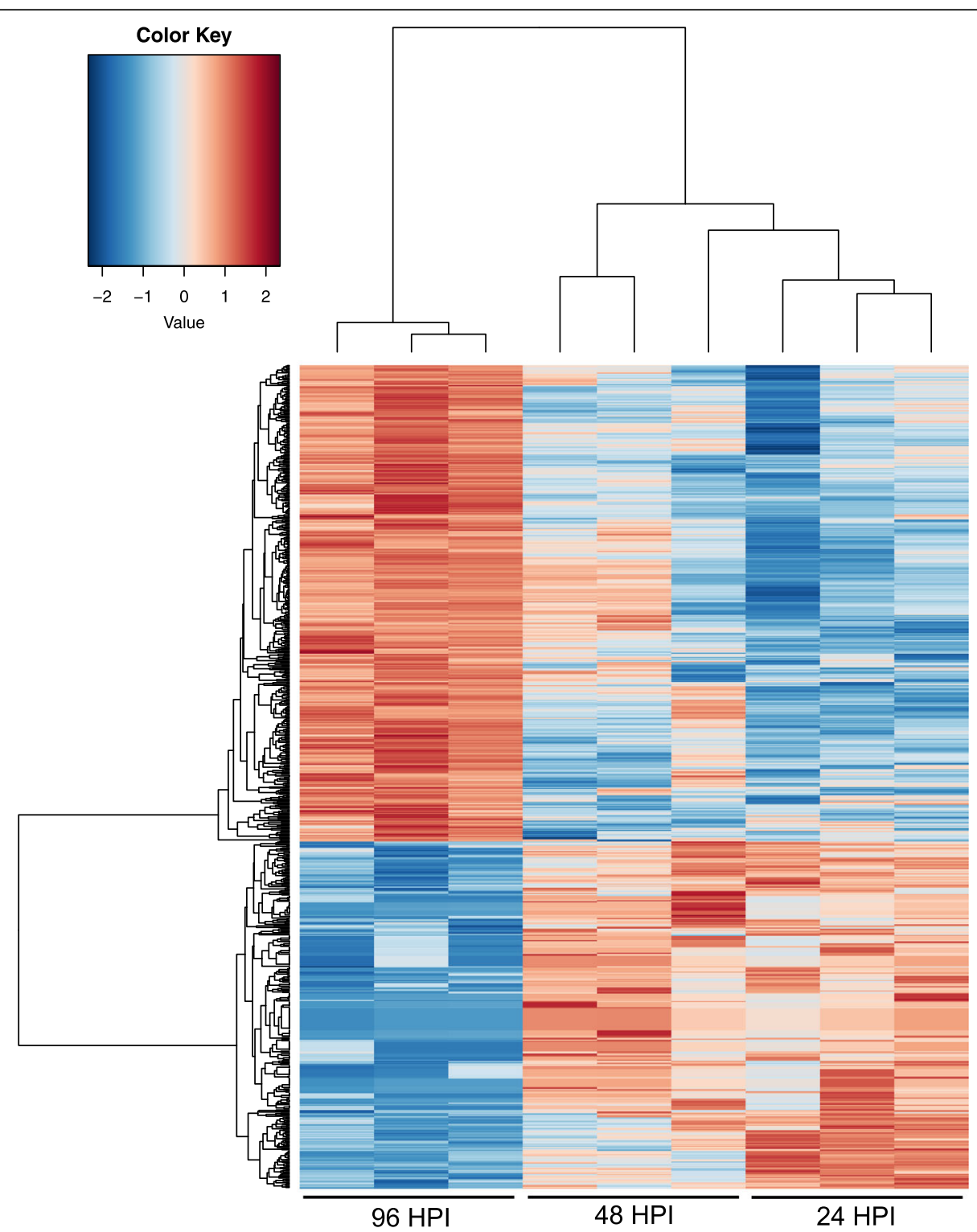

Fig. 3 Summary heat map showing all differentially expressed genes (DEGs) in the comparison of the 96 hpi timepoint to the average of the 24 and 48 hpi timepoints. Columns represent replicates of each timepoint and rows represent individual genes. The tree above the heatmap demonstrates the hierarchical clustering of the samples. Red is used to represent genes which were up-regulated, and blue is used to represent genes which were down-regulated

roles of individual genes can often be lost within the global view. To address this, up- and downregulated genes were manually analyzed using Protein BLAST (blastp). The two LATE genes most differentially expressed over the course of infection $(\operatorname{logFC}=7.3-7.9)$ were surprisingly not classical virulence genes, but development-specific fungal lectins referred to as Ssp1 (Sscle10g079320) and Ssa (Sscle01g001830) (Additional file 2: Table S2). The precise function of these lectins is unknown, but both were found to be abundant in sclerotia, and their upregulation late in infection may indicate a shift towards sclerotial formation [33, 34]. Sixteen genes, including Ssp1 and Ssa, which were up-regulated late during infection, were also identified in a previous proteomic analysis as highly abundant gene products in the liquid exudates of S. sclerotiorum sclerotia [35] (Additional file 5: Table S4). The overlap of these genes upregulated at 96 hpi and the abundance of their products in sclerotial exudates provides evidence that the pathogen is likely shifting focus at the later stages of infection from virulence/ colonization to survival structure formation.

Three of the EARLY genes which are upregulated during early infection make up the critical components of nitrate metabolism in S. sclerotiorum (Additional file 2: 


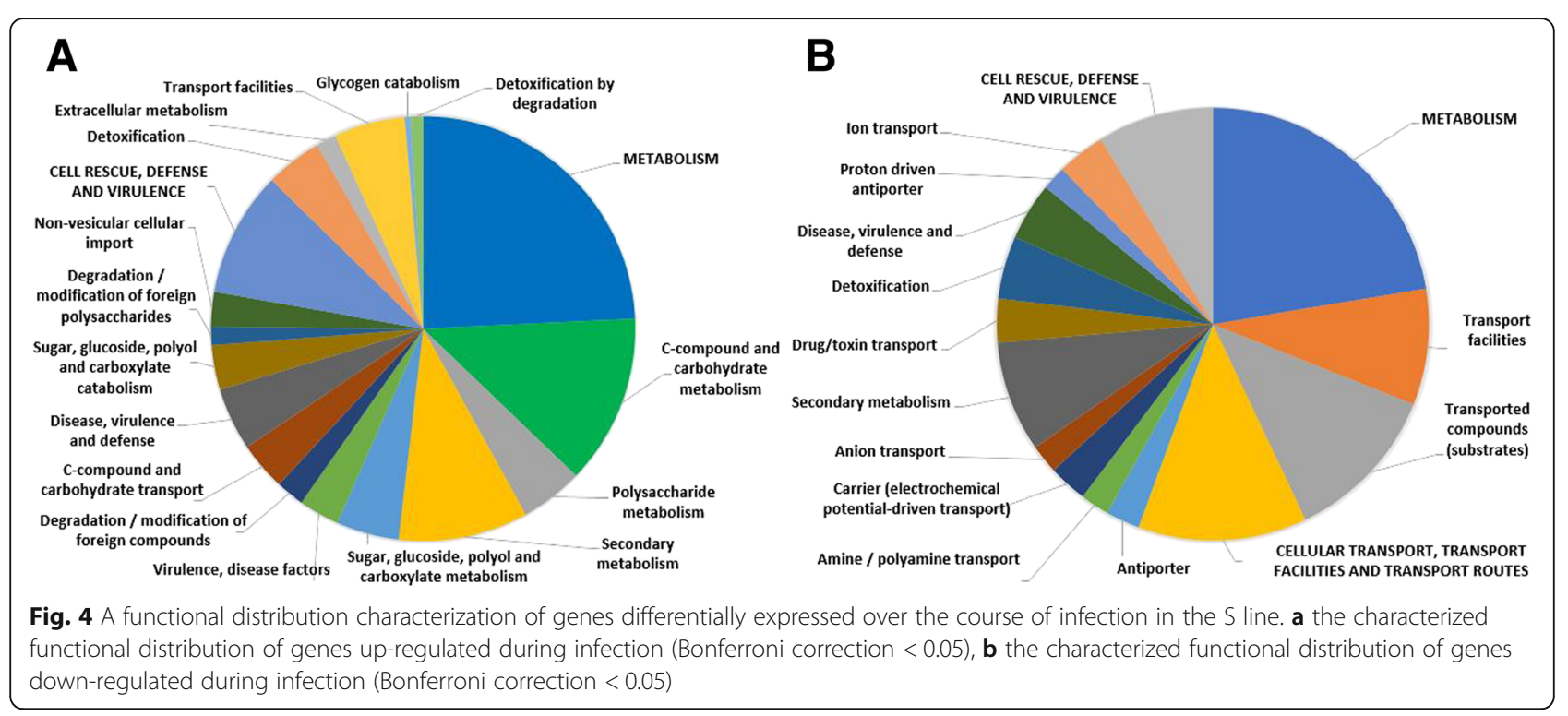

Table S2). These genes, consisting of a nitrate transporter (Sscle02g013580) which transports nitrate into the cytoplasm, a nitrate reductase (Sscle01g005230) that converts nitrate to nitrite, and a nitrite reductase (Sscle02g016460) which converts nitrite to ammonia, are most highly expressed during early infection and show a steep reduction in expression by $96 \mathrm{hpi}(\operatorname{logFC}=-2.25-3)$. The potential importance of nitrogen metabolism in early infection is similarly reflected in the early upregulation of S. sclerotiorum's urea active transporter (Sscle05g043930) and urease (Sscle05g047190) as well. This early expression pattern may be the result of relatively low nitrogen availability for the pathogen following penetration.

\section{S. sclerotiorum genes differentially regulated in-planta}

To identify important pathogenicity components in $S$. sclerotiorum, a comparative expression analysis was performed between each timepoint of the $\mathrm{S}$ line infection (24, 48, and $96 \mathrm{hpi})$ and the culture control (C). DEG's (False discovery rate $(\mathrm{FDR})<0.05$; Average RPKM $>1$; and $\log _{2}$ fold change $(\operatorname{logFC}) \geq 1$ or $\left.\leq-1\right)$ were generated and categorized using BlastGo annotation and their predicted role in the infection cycle. To focus on genes specifically induced during soybean infection, only genes with at least one time-point containing a $\operatorname{logFC}$ greater than one were considered. Over all three timepoints of infection, a total of 2093 putative genes showed positive regulation in-planta (Additional file 6: Table S5). Of these genes, 262, 120, and 505 were up-regulated exclusively at 24, 48, and 96 HPI, respectively, and 728 were up-regulated at all timepoints (Fig. 5).

\section{Cell wall degrading (CWD) and other hydrolytic enzymes}

The successful degradation of plant cell walls is a pivotal step in both the colonization of host plants and in the release of sugars to be metabolized by fungal pathogens. S. sclerotiorum's genome contains numerous genes that code for CWDEs [23], though, only a portion of this repertoire appears to be positively regulated during infection of soybean (Table 2).

Of the CWDEs, those showing pectinolytic activity, such as endo- or exo-polygalacturonases (PGs), have garnered particular attention given their demonstrated importance in virulence across a range of fungal pathogens [19, 36, 37]. S. sclerotiorum's genome contains nine previously identified PGs: Sspg1 (Sscle16g108170), Sspg2

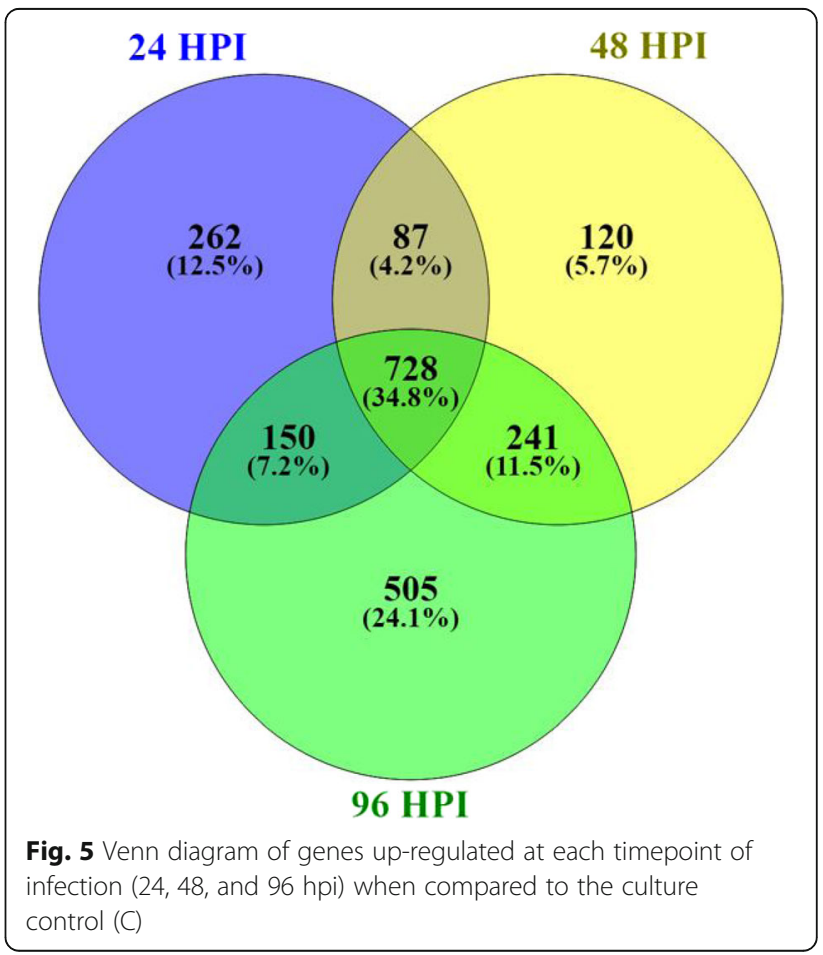


or Sspg1b (Sscle03g022740), Sspg3 (Sscle09g070580), Sspg5 (Sscle02g018820), Sspg6 (Sscle12g088720), Ssxpg1 (Sscle02g 018610), Ssxpg2 (Sscle04g035440), and two uncharacterized putative exo-polygalacturonases (Sscle05g046840 and Sscle05g040500) [19, 20]. The upregulation of all $9 \mathrm{pu}-$ tative S. sclerotiorum PGs can be seen as the infection progresses, with the exception of Sspg1, Sspg3, and Sscle05g046840, which are expressed consistently at all timepoints (Average $\operatorname{logFCs}=\sim 8, \sim 5.5$, and $\sim 4.5$, respectively), all other PGs show the greatest upregulation at 96 HPI (Additional file 7: Table S6).

During $S$. sclerotiorum infection on many hosts, the cuticle constitutes the first physical barrier to pathogen invasion. Given the nature of the cut-petiole inoculation technique used in this study, cutinase activity may not be required. However, most of the putative cutinases were either consistently induced at relatively high levels throughout infection (Sscle11g084380 and Sscle15g 102320) or most induced at 96 HPI after the infection reached the main stem (Sscle02g011950) (Additional file 7: Table S6). Whether this is due to a consistent need to form lesions on the surface of the plant or a secondary purpose, such as interactions with other hydrophobic lipid substrates during colonization is unknown.

Proteases are hydrolytic enzymes which have been shown to act as important virulence factors in a variety of fungal plant pathogens through the degradation of proteins involved in the immune response of the host [38]. A total of 34 proteases were upregulated during this study (Additional file 7: Table S6). During early

Table 2 Hydrolytic enzymes up-regulated in-planta

\begin{tabular}{|c|c|c|c|c|}
\hline Substrate & $\begin{array}{l}\text { Hydrolytic } \\
\text { Enzymes }\end{array}$ & $\begin{array}{l}\text { DEGs in } \\
\text { Category }\end{array}$ & $\begin{array}{l}\text { Total Genes } \\
\text { in Category }\end{array}$ & $\begin{array}{l}\% \text { Up- } \\
\text { regulated }\end{array}$ \\
\hline Lipids/Cutin & $\begin{array}{l}\text { Lipid } \\
\text { Degradation }\end{array}$ & 33 & 46 & $71.7 \%$ \\
\hline \multirow[t]{7}{*}{ Polysaccharides } & $\begin{array}{l}\text { Pectin } \\
\text { Degradation }\end{array}$ & 29 & 32 & $90.6 \%$ \\
\hline & $\begin{array}{l}\text { Cellulose } \\
\text { Degradation }\end{array}$ & 26 & 46 & $56.5 \%$ \\
\hline & $\begin{array}{l}\text { Hemicellulose } \\
\text { Degradation }\end{array}$ & 28 & 28 & $100.0 \%$ \\
\hline & $\begin{array}{l}\text { Starch } \\
\text { Degradation }\end{array}$ & 5 & 8 & $62.5 \%$ \\
\hline & $\begin{array}{l}\text { Mannan } \\
\text { Degradation }\end{array}$ & 10 & 18 & $55.6 \%$ \\
\hline & $\begin{array}{l}\text { Callose } \\
\text { Degradation }\end{array}$ & 1 & 2 & $50.0 \%$ \\
\hline & $\begin{array}{l}\text { Arabinogalactan } \\
\text { Degradation }\end{array}$ & 9 & 10 & $90.0 \%$ \\
\hline Proteins/Peptides & $\begin{array}{l}\text { Protein } \\
\text { Degradation }\end{array}$ & 34 & 73 & $46.6 \%$ \\
\hline
\end{tabular}

The hydrolytic enzymes up-regulated at some time point of infection. Enzymes were putatively assigned to specific substrates based on Blast2GO annotation or characterized homologues infection, a previously characterized non-aspartyl acid protease (acp1; Sscle11g082980) was found to be the most upregulated $(\operatorname{logFC}=6.22$ at $24 \mathrm{hpi})$ [39]. The largest group of proteases induced during infection were serine proteases, which were categorized as either carboxypeptidases, subtilisin-like proteins, or tripeptidyl peptidases, the latter two of which both belong to the subtilisin superfamily. Serine proteases have been characterized as virulence determinants in a large number of phytopathogenic fungi [40-42] and of the 17 serine proteases identified in this analysis, all 17 showed the highest expression at the initial stages of infection $(24 \mathrm{hpi})$. Two other proteases were also upregulated during infection and are homologous to proteases involved in pathogenesis. An aspartyl (acid) protease, Sscle04g035550, was upregulated at all timepoints and was found to contain a SAPs domain (cd05474) commonly associated with plant pathogenic protease activity [43]. Another aspartate protease, Sscle07g058540, was the second most upregulated protease at $24 \mathrm{hpi}$ and shows homology to several aspergillopepsin-like proteins (cd06097) whose activity is important in invasive aspergillosis of humans [44] (Additional file 7: Table S6).

\section{Secondary metabolite synthesis and detoxification}

Many genes related to secondary metabolite (SM) synthesis and detoxification were up-regulated during at least one time-point of the infection. Although the function of a vast majority of these SMs is unknown, extensive study of S. sclerotiorum's close relative Botrytis cinerea as well as other fungal pathogens have characterized many as phytotoxic and/or important in pathogenesis $[45,46]$. Polyketide synthase (PKS) and Non-ribosomal peptide synthase (NRPS) appear to be the major enzymes associated with SM synthesis in S. sclerotiorum, and make-up 66.6 and $22.2 \%$, respectively, of the SM synthesis genes found to be positively regulated in this study. Two PKSs (SsPKS4: Sscle05g048020 and SsPKS11: Sscle15g105000) were expressed to higher levels at all timepoints after inoculation, as compared to the in vitro control. Two other PKSs (SsPKS10: Sscle04g032810 and SsPKS15: Sscle14g097860), which saw no induction during the infection of $B$. napus [24], were highly up-regulated $(\operatorname{logFC}=\sim 4)$ at $24 \mathrm{HPI}$, indicating a possible role in early infection of soybean. A single phytoene synthase (SsPHS1: Sscle02g017510) was also upregulated at all timepoints (Additional file 8: Table S7).

Although PKSs and NRPSs are the primary genes involved in SM synthesis, cytochrome P450s (CYP450s) play a pivotal role in both the biosynthesis of fungal mycotoxins and the detoxification of host metabolites through the conversion of potentially toxic compounds to more hydrophilic derivatives $[47,48]$. A large number of CYP450s were positively regulated at some timepoint of the soybean infection, with $16.2 \%(6 / 37)$ and $37.8 \%$ 
(14/37) of the genes showing up-regulation at only 24 and 96 hpi, respectively. The most up-regulated CYP450 at 24 and 48 hpi was Sscle04g033880, a gene showing homology to pisatin demethylase in Aspergillus lentulus (Additional file 9: Table S8). Another CYP450, Sscle08g067130, was highly induced throughout infection of both B. napus [24] and in this study in soybean, indicating a potentially conserved requirement during infection of both crops, whereas Sscle05g045810, which was highly upregulated at all timepoints during this study, upregulation of this gene was not observed during B. napus infection. [24] (Additional file 9: Table S8).

Botcinic acid is an important virulence factor of $B$. cinerea, and despite finding the orthologous SM cluster in S. sclerotiorum, previous studies have failed to identify the toxin in S. sclerotiorum [49] or the upregulation of the pivotal PKS genes in-planta [24]. However, we found all 13 orthologs of the botcinic acid gene cluster (Bcboa1-13) to be upregulate in this study, with all showing the highest upregulation at 96 hpi (Fig. 6). Nearly all of the most upregulated SM synthesis genes and CYP450s belong to this cluster, including the two PKS genes directly implicated in botcinic acid biosynthesis (Sscle15g106510 and Sscle15g106480), an additional PKS (Sscle15g106520), a putative FAD-dependent monooxygenase (Sscle15g
106490), and three CYP450's (Sscle15g106540, Sscle15g106530, and Sscle15g106500).

Along with the multifaceted role of CYP450's in SM metabolism, fungal pathogens require a suite of other enzymes to detoxify the fungicidal metabolites released by their hosts. This can be achieved through enzymatic modification of the metabolites or through the activity of transporters which can prevent the accumulation of harmful toxins [32]. By far the most upregulated detoxification enzyme at all timepoints was the brassinin glucosyltransferase Ssbgt1 (Sscle01g003110; $\log F C=7.2-8.8$ ). Ssbgt1is expressed in response to the production of a variety of plant phytoalexins in the host, and was shown to specifically degrade the antimicrobial compound brassinin via glucosylation [50]. Ssbgt1 was observed to be the most upregulated detoxification enzyme during the S. sclerotiorum infection of $B$. napus as well, indicating a strong phytoalexin response in both hosts [24] (Additional file 6: Table S5).

Laccases are a class of copper-containing oxidase enzymes that are known to oxidize a wide range of phenols as their substrates [51]. A recent analysis of the S. sclerotiorum-soybean pathosystem identified phenolic compounds generated in the phenylpropanoid pathway as a pivotal component of soybean resistance, thus highlighting a potentially critical role

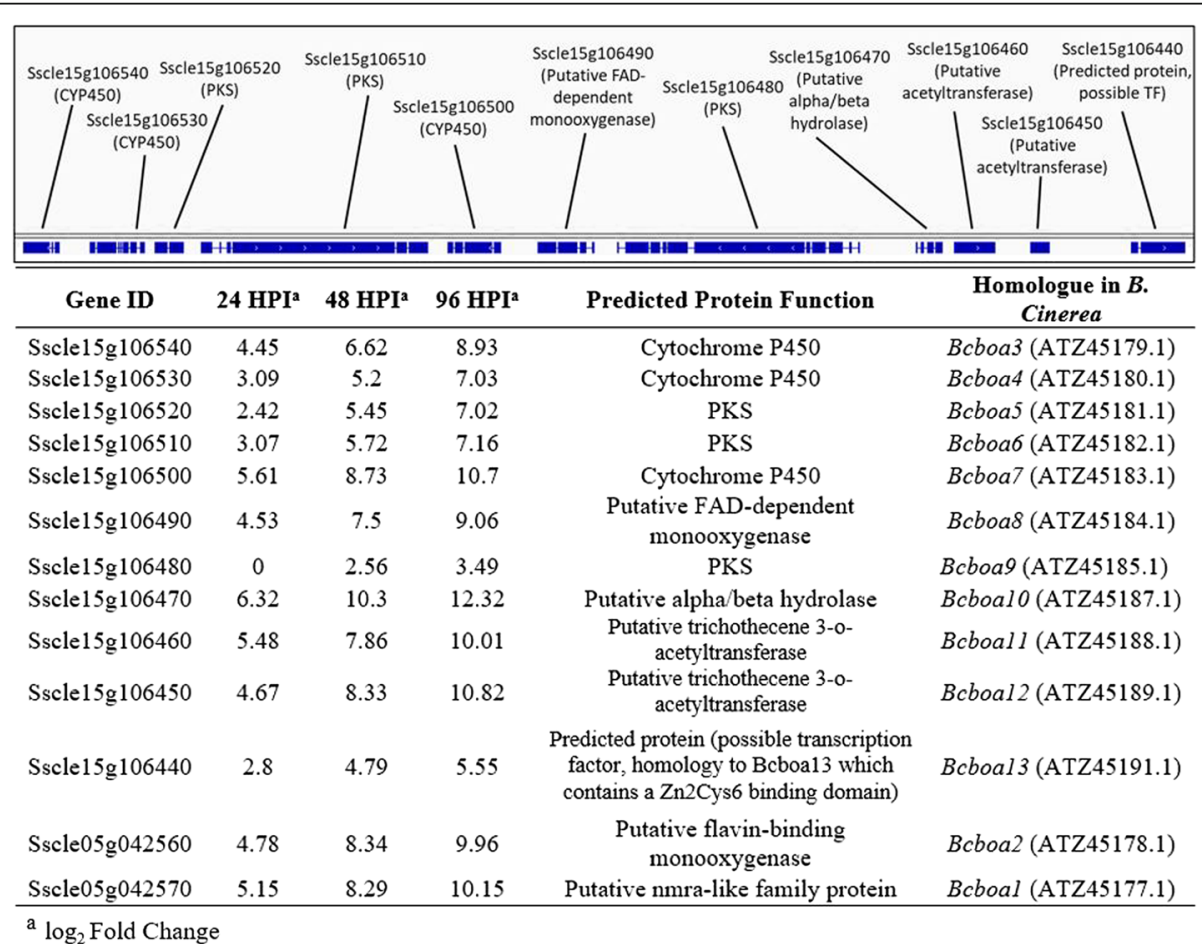

Fig. 6 Secondary metabolite cluster identified on chromosome 15 of S. sclerotiorum. The cluster contains three putative Cytochrome P450s (Sscle15g106540, - 30, - 00), three putative PKSs (Sscle15g106520, - 10, - 480), two putative acetyltransferases (Sscle15g106460 and - 50), a putative FAD-dependent monooxygenase (Sscle15g106490), a putative alpha/beta hydrolase (Sscle15g106470), and a predicted protein of unknown function (Sscle15g106440). The gene loci, logFCs (compared to culture), predicted function, and homologue in B. cinerea of each gene are shown. Sscle05g042560 and Sscle05g042570 appear within this gene cluster in B. cinerea, but are found on chromosome 5 of S. sclerotiorum 

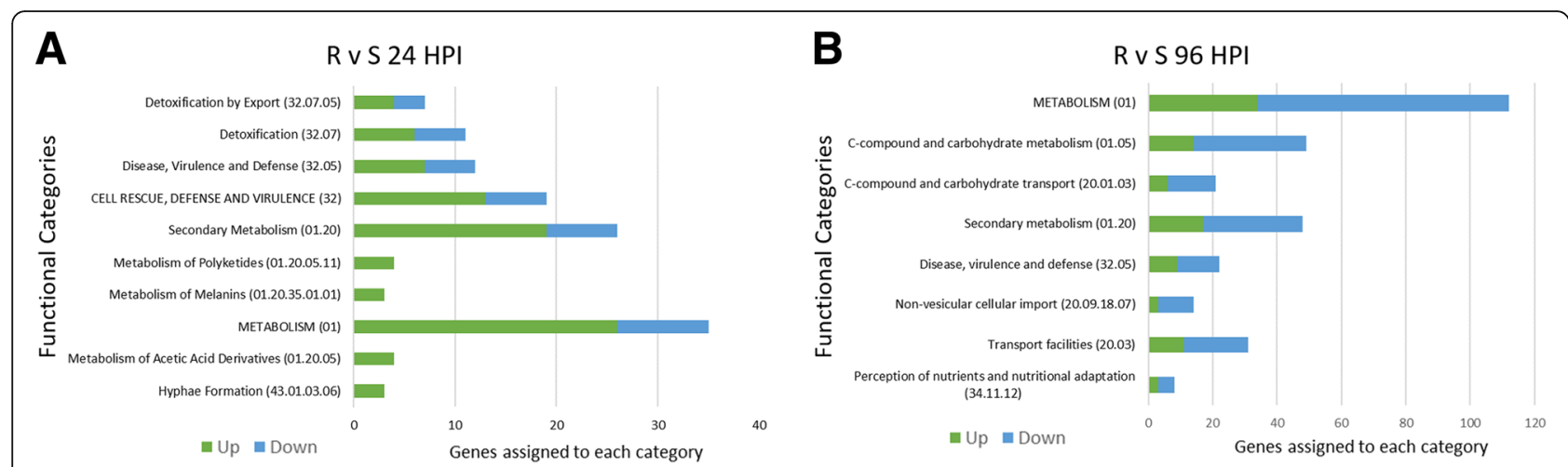

Fig. 7 Functional distribution of differentially expressed in the R and S lines at 24 (a) and 96 hpi (b). Green regions of each bar represent genes which were up-regulated in the $\mathrm{R}$ line. Blue regions of each bar represent genes which were down-regulated in the $\mathrm{R}$ line

for laccases in suppressing this immune response [30]. Only two laccases, a putative laccase 2 (Sscle03g023030) and a probable laccase precursor (Sscle13g092370), were upregulated in comparison to culture, the latter of which was only upregulated at $48 \mathrm{hpi}$. The former laccase gene, Sscle03g 023030, is notable both because of its impressive upregulation in-planta and because it was not documented in the transcriptomic analysis of B. napus [24] or P. vulgaris [25]. As well as being up-regulated at all timepoints, Sscle03g 023030 is among the most differentially expressed between early and late infection, with its greatest upregulation at 24 hpi $(\operatorname{logFC}=7.8)$ and lowest at 96 hpi $(\operatorname{logFC}=2.8)($ Table 3$)$.

Glutathione S-transferases (GSTs) are known for their ability to detoxify a wide range of toxic compounds through glutathione conjugation [52]. Six GSTs were upregulated in this analysis compared to culture conditions (Sscle01g 005000, Sscle08g067590, Sscle06g051110, Sscle10g075830,
Sscle15g104750, Sscle06g053300), forming the largest group of detoxification enzymes induced during infection. Compared to other detoxification enzymes, these six GSTs were expressed at relatively consistent levels throughout infection, potentially indicating a constant pressure from plant phytotoxins throughout infection (Table 3).

This pattern is largely conserved within the three 2-nitropropane dioxygenase genes (Sscle03g027760, Sscle12g087340, and Sscle11g085500) which constitute the second largest group of detoxification enzymes upregulated in-planta (Table 3).

As previously discussed, transporter proteins, especially within the $\mathrm{ABC}$ transporter class, can play an important role in the efflux of fungicidal phytotoxins during infection [53, 54]. Of the eight putative $\mathrm{ABC}$ transporters up-regulated during infection, three (Sscle01g004040, Sscle02g016430, Sscle14g097690) were among the most

Table 3 Detoxification enzymes up-regulated in-planta

\begin{tabular}{|c|c|c|c|c|}
\hline Gene ID & $24 \mathrm{HPI}^{\mathrm{a}}$ & $48 \mathrm{HPl}^{\mathrm{a}}$ & $96 \mathrm{HPI}^{\mathrm{a}}$ & Blast2GO Description \\
\hline Sscle03g027760 & 1.98 & 1.7 & 1.83 & 2-nitropropane dioxygenase \\
\hline Sscle12g087340 & - & - & 1.93 & 2-nitropropane dioxygenase \\
\hline Sscle11g085500 & - & - & 1.13 & 2-nitropropane dioxygenase protein \\
\hline Sscle01g007130 & 2.71 & 3 & 4.64 & carbon-nitrogen hydrolase \\
\hline Sscle08g067590 & - & - & 1.66 & glutathione s-transferase \\
\hline Sscle06g051110 & 1.31 & 1.09 & 1.06 & glutathione s-transferase \\
\hline Sscle10g075830 & - & 1.44 & 1.74 & glutathione s-transferase \\
\hline Sscle15g104750 & 5.06 & 4.73 & 6.36 & glutathione s-transferase \\
\hline Sscle06g053300 & 1.39 & 1.64 & 1.93 & glutathione s-transferase kappa 1 \\
\hline Sscle01g005000 & 3.8 & 3.43 & 3.29 & glutathione transferase \\
\hline Sscle01g003110 & 7.17 & 8.66 & 8.79 & udp-glucosyltransferase (brassinin) \\
\hline Sscle03g023030 & 7.08 & 4.84 & 2.83 & laccase 2 \\
\hline Sscle13g092370 & - & 3.65 & - & multicopper oxidase \\
\hline
\end{tabular}

${ }^{\mathrm{a}} \log _{2}$ Fold Change

The logFC and Blast2GO description of genes putatively assigned as detoxification enzymes within S. sclerotiorum. LogFC values were generated through the comparison of individual timepoints of the $\mathrm{S}$ line infection and the culture control 
up-regulated transporters at any timepoint and all were most induced during early infection (Additional file 10: Table S9). The most up-regulated of those three, Sscle01g004040, shares high homology (88\%) to Bmr3, a transporter characterized in $B$. cinerea and found to be strongly induced following exposure to a variety of fungicidal toxins, including mepanipyrim, the grapevine phytoalexin resveratrol, and two dicarboximides [55]. The second, Sscle02g016430, encodes a homolog to Bmr1, another $\mathrm{ABC}$ transporter closely related to $\mathrm{Bmr} 3$, and was most highly expressed at 48 hpi. The third, Sscle14g 097690, is a homolog of the B. cinerea gene BcatrB, known to be important in fungal tolerance to the phytoalexins camalexin and resveratrol [54, 56]. Sscle14g097690 shared the same expression pattern as the other two, demonstrating the greatest upregulation at $48 \mathrm{hpi}$ (Additional file 10: Table S9). The upregulation of these various mechanisms of detoxification indicates a strong phytoalexin pressure during S. sclerotiorum infection of soybean, which agrees with previous work highlighting the production of antifungal compounds in soybean during SSR infection [30].

\section{Transcription factors}

Transcription factors (TFs) are proteins containing at-least one DNA-binding domain (DBD) that act as pivotal regulators of gene expression throughout the lifecycle of all Eukaryotes. Because of the potentially positive or inhibitory role that TFs can have on the pathways that they regulate, all DEG's $(\operatorname{logFC}>1$ or $<-1)$ were considered for this analysis, as opposed to only those showing positive regulation. Although many TFs have been annotated, only Ssfkh1 (Sscle06g049780), Ssfoxe2 (Sscle05g046830), and Pac1 (Sscle06g049830) have been functionally characterized in S. sclerotiorum $[8,57,58]$. Of the 197 putative TFs identified in the S. sclerotiorum genome, 68 appear to be differentially regulated during infection $(\sim 34.5 \%)$ (Additional file 11: Table S10). Interestingly, neither $S s f k h 1$ or Pac1 is differentially expressed, despite their demonstrated role in virulence. Two zinc finger containing TFs very close to one another on chromosome 16 (Sscle16g110450 and Sscle16g110180) and another on chromosome 9 (Sscle09g071930) are the most differentially regulated TFs at $24 \mathrm{HPI}$, with $\operatorname{logFCs}$ of $-5.12,-3.43$, and 3.02, respectively (Additional file 11: Table S10).

\section{Putative secreted effectors}

Unlike their filamentous cousins, the oomycetes, true fungi lack any conserved domains, such as the RXLR motif, to help in the identification of their effectors [59]. However, other factors were utilized in previous studies to single out putative effector proteins in S. sclerotiorum [22, 60].
Of the 4602 DEGs identified in this study, 57 were identified as putative secreted effectors. Of these 57 genes, only 18 were differentially regulated during the course of infection (early v. late) (Table 4). The large number of putative effectors that are not differentially expressed over the course of infection could point to a more constitutive expression of effectors in S. sclerotiorum than is commonly seen in biotrophic and hemibiotrophic fungi, which often alter effector expression as they transition between stages of infection (i.e. appressoria formation, penetration of invasive hyphae, differentiation into necrotrophic hyphae) [61-63].

The previously characterized Ssv263 (Sscle03g028510) [15] has the largest $\operatorname{logFC}$ of any putative effector compared to culture conditions $(24 \mathrm{hpi}=12.19,48 \mathrm{hpi}=10.01$, and $96 \mathrm{hpi}=6.15)$ and early v. late infection $(\log \mathrm{FC}=-$ 5.32), suggesting its likely importance earlier in the infection process. This was also true for a Rhs repeat-containing protein (Ss-rhs1; Sscle06g049430) (71), found to be important for sclerotial development and hyphal infection (Table 4). Ssnep2 (Sscle12g090490), which was characterized as necrosis and ethylene-inducing peptide on Nicotiana benthamiana [16], was up-regulated at all timepoints of the infection (Table 4). Ssssvp1 (Sscle01g003850) and Sscp1 (Sscle16g107670), two fungal proteins shown to induce programmed cell death in plants $[18,64]$, were highly upregulated at all timepoints in comparison to culture, but showed peak expression at 96 hpi (Table 4). The S. sclerotiorum integrin-like gene (Ssitl; Sscle08g068500), a secreted effector known to suppress jasmonic/ethylene (JA/ET) signaling [17], was only upregulated as compared to culture at 96 hpi (Table 4).

Two uncharacterized genes encoding CFEM domain-containing proteins were also identified in this study, the first of which (Sscle07g055350) was among the most upregulated during infection, with $\operatorname{logFCs}>8$ at all timepoints, while the second (Sscle06g050280) showed strong induction at the later stages of infection compared to early $(\log F C=5.04)$. Two genes with no conserved domains and with no known nor characterized homology to other effectors, Sscle05g045060 and Sscle06g048920, were the third and fourth most upregulated at $24 \mathrm{hpi}$, respectively, and demonstrated consistently high expression throughout infection. Two other highly upregulated genes, Sscle06g055310 and Sscle11g080900, share 99\% homology with one another and are closely related to an Immunoglobin E (IgE) binding proteins in Aspergillus fumigatus ( $40 \%$ identity) (Table 4).

To avoid detection and protect their cell walls from enzymatic degradation, many fungal pathogens have evolved strategies to bind their stray chitin to avoid the induction of plant pattern triggered immunity (PTI) and/or plant 
Table 4 Putative secreted effectors up-regulated during infection

\begin{tabular}{|c|c|c|c|c|c|}
\hline Gene ID & $\begin{array}{l}24 \\
\mathrm{HPI}\end{array}$ & $\begin{array}{l}48 \\
\mathrm{HPI}\end{array}$ & $\begin{array}{l}96 \\
\mathrm{HPI}\end{array}$ & $\begin{array}{l}\text { Dis. } \\
\text { Progress } \\
\end{array}$ & Notes/Citations \\
\hline Sscle03g028510 & 12.19 & 10.01 & 6.15 & -4.98 & Possible virulence factor characterized in B. napus infection (Ssv263) [15]. \\
\hline Sscle07g055350 & 8.03 & 8.87 & 10.83 & - & Contains a CFEM domain (pfam05730). Found to be up-regulated in Brassica infection [24] \\
\hline Sscle05g045060 & 8.4 & 8.84 & 9.09 & - & Identified as a predicted effector by Derbyshire et al. 2017 [58]. \\
\hline Sscle06g048920 & 8.68 & 9.33 & 8.24 & - & Identified as a predicted effector by Derbyshire et al. 2017 [58]. \\
\hline Sscle06g055310 & 7.72 & 8.02 & 7.76 & - & $\begin{array}{l}\text { Related to Immunoglobin E (IgE) binding proteins in Aspergillus fumigatus ( 40\% identity). } \\
\text { Homologue to Sscle11g080900 ( } 99 \% \text { identity). }\end{array}$ \\
\hline Sscle11g080900 & 7.25 & 7.64 & 7.37 & - & $\begin{array}{l}\text { Related to Immunoglobin E (lgE) binding proteins in Aspergillus fumigatus ( 40\% identity). } \\
\text { Homologue to Sscle06g055310 ( } 99 \% \text { identity). }\end{array}$ \\
\hline Sscle16g 107670 & 6.97 & 6.68 & 7.15 & - & $\begin{array}{l}\text { A gene containing a cerato-platanin domain (pfam07249) which was characterized as Sscp1 and } \\
\text { found to be important in full virulence of S. sclerotiorum [62] }\end{array}$ \\
\hline Sscle08g068200 & 6.29 & 7.05 & 6.52 & - & $\begin{array}{l}\text { Contains two chitin recognition domains (pfam00187) and a fungal cellulose binding domain } \\
\text { (pfam00734). }\end{array}$ \\
\hline Sscle01g003850 & 4.96 & 6.03 & 7.48 & 1.98 & $\begin{array}{l}\text { Characterized as a virulence gene in S. sclerotiorum (SSSSvp1). Binds with a subunit of the } \\
\text { cytochrome b-c1 complex of the mitochondrial respiratory chain and prevents subcellular } \\
\text { localization into the mitochondria, subsequently leading to plant cell death [18]. }\end{array}$ \\
\hline Sscle12g090490 & 5.17 & 5.78 & 5.9 & - & A necrosis and ethylene-inducing peptide (SsNEP2) found to induce cell death in plants [16]. \\
\hline Sscle05g041050 & 3.43 & 5.52 & 7.66 & 3.19 & Identified as a predicted effector by Derbyshire et al. 2017 [58]. \\
\hline Sscle03g024000 & 5.15 & 4.72 & 4.81 & - & $\begin{array}{l}\text { Shares 59\% identity with Colletotrichum hingginsianum effector candidate } 91 \text { (CHEC91) [104] and a } \\
\text { Colletotrichum incanum gene categorized as a "hypersensitive-response inducing protein." }\end{array}$ \\
\hline Sscle08g064180 & 4.29 & 5.26 & 4.97 & - & Identified as a predicted effector by Derbyshire et al. 2017 [58]. \\
\hline Sscle03g022790 & 2.69 & 5.47 & 5.7 & - & $\begin{array}{l}\text { Contains a fungal hydrophobin domain (pfam06766). Possibly involved in mediating the interaction } \\
\text { of fungal tissue and the plant. Often connected to the outside of fungal conidia or on the } \\
\text { hyphal wall. }\end{array}$ \\
\hline Sscle11g082980 & 6.22 & 3.86 & 3.57 & - & $\begin{array}{l}\text { A non-aspartyl acid protease (acp1) found to be expressed during S. sclerotiorum infection of } \\
\text { sunflower cotyledons. [38] }\end{array}$ \\
\hline Sscle06g049430 & 6.57 & 3.11 & 3.72 & - & $\begin{array}{l}\text { A secretory Rhs repeat-containing protein (Ss-Rhs1) found to be important in sclerotial development } \\
\text { and hyphal infection. [87] }\end{array}$ \\
\hline Sscle04g040080 & 3.49 & 3.76 & 5.08 & - & $\begin{array}{l}\text { Identified as a predicted effector by Derbyshire et al. } 2017 \text { [58]. Contains a protein domain of } \\
\text { unknown function (DUF3129; pfam11327). }\end{array}$ \\
\hline Sscle08g063910 & 3.95 & 3.14 & 4.18 & - & Found to be up-regulated in Brassica infection [24]. \\
\hline Sscle07g061770 & - & 4.19 & 5.11 & - & Identified as a predicted effector by Derbyshire et al. 2017 [58]. \\
\hline Sscle10g075140 & - & 5.37 & 3.72 & - & Identified as a predicted effector by Derbyshire et al. 2017 [58]. \\
\hline Sscle06g052360 & 3.52 & 2.63 & 2.82 & - & Identified as a predicted effector by Derbyshire et al. 2017 [58]. \\
\hline Sscle15g106630 & 4.34 & 2.76 & 1.76 & -1.82 & Found to be up-regulated in Brassica infection [24]. \\
\hline Sscle16g111080 & 3.77 & 2.73 & 1.71 & -1.56 & $\begin{array}{l}\text { A putative chorismate mutase which is expressed in S. sclerotiorum infection of Brassica and is } \\
\text { predicted to interfere with salicylic acid (SA) signaling in infected plants [88]. }\end{array}$ \\
\hline Sscle05g042890 & 2.31 & 2.76 & 2.51 & - & $\begin{array}{l}\text { Contains a Lytic polysaccharide mono-oxygenase, cellulose-degrading domain (LPMO-10; } \\
\text { pfam03067), related to cellulose degradation. This domain was previously characterized as a } \\
\text { chitin binding domain. }\end{array}$ \\
\hline Sscle01g000190 & 2.38 & 2.4 & 2.61 & - & $\begin{array}{l}\text { Contains a pyrroline-5-carboxylate reductase domain (pfam14748). Possibly involved in proline } \\
\text { biosynthesis. }\end{array}$ \\
\hline Sscle16g107890 & 3.21 & 3.58 & - & - & Identified as a predicted effector by Derbyshire et al. 2017 [58]. \\
\hline Sscle07g062010 & 1.38 & 2.82 & 2.29 & - & $\begin{array}{l}\text { Contains a glycosyl hydrolases, family } 18 \text { (GH18) type II chitinase. Found to be up-regulated in } \\
\text { B. napus infection [24] }\end{array}$ \\
\hline Sscle07g058780 & 1.44 & 2.2 & 2.18 & - & Found to be up-regulated during Arabidopsis infection [105]. \\
\hline Sscle04g035160 & - & 2.69 & 3.1 & - & Identified as a predicted effector by Derbyshire et al. 2017 [58]. \\
\hline Sscle13g096120 & 3.42 & - & 2.07 & - & Identified as a predicted effector by Guyon et al. 2014 [22]. \\
\hline Sscle08g065470 & 2.24 & 1.56 & 1.66 & - & $\begin{array}{l}\text { Contains an amidase domain (pfam01425). Identified as a predicted effector by Guyon et al. } \\
2014 \text { [22]. }\end{array}$ \\
\hline Sscle06g054400 & - & 1.72 & 3.11 & - & Identified as a predicted effector by Derbyshire et al. 2017 [58]. \\
\hline
\end{tabular}


Table 4 Putative secreted effectors up-regulated during infection (Continued)

\begin{tabular}{|c|c|c|c|c|c|}
\hline Gene ID & $\begin{array}{l}24 \\
\mathrm{HPI}\end{array}$ & $\begin{array}{l}48 \\
\mathrm{HPI}\end{array}$ & $\begin{array}{l}96 \\
\mathrm{HPI}\end{array}$ & $\begin{array}{l}\text { Dis. } \\
\text { Progress }\end{array}$ & Notes/Citations \\
\hline Sscle10g078230 & - & 3.05 & 1.71 & - & $\begin{array}{l}\text { A putative salicylate hydrolase. Contains salicylate 1-monooxygenase (TIGRO3219) and FAD binding } \\
\text { (pfam01494) domains. }\end{array}$ \\
\hline Sscle08g064590 & - & 2.17 & 2.53 & - & Identified as a predicted effector by Derbyshire et al. 2017 [58]. \\
\hline Sscle12g088370 & - & 1.43 & 3.16 & 2.6 & Identified as a predicted effector by Guyon et al. 2014 [22]. \\
\hline Sscle06g054180 & - & - & 4.37 & 4.53 & Contains a Lysin motif (smart00257). Found to be up-regulated in Brassica infection [24]. \\
\hline Sscle07g057820 & 1.52 & 1.27 & 1.31 & - & $\begin{array}{l}\text { A likely subtilisin-like serine protease. Also contains a peptidase inhibitor domain (pfam05922), } \\
\text { suggesting that it may be at the very least a temporary protease inhibitor. }\end{array}$ \\
\hline Sscle06g050820 & 2.08 & - & 1.96 & - & Identified as a predicted effector by Derbyshire et al. 2017 [58]. \\
\hline Sscle07g062060 & 1.19 & 1.32 & 1.46 & - & Identified as a predicted effector by Derbyshire et al. 2017 [58]. \\
\hline Sscle01g007640 & 1.2 & 1.23 & 1.22 & - & $\begin{array}{l}\text { A serine protease inhibitor containing a Peptidase inhibitor } 19 \text { domain (PF05922) which was } \\
\text { expressed during infection of Arabidopsis [22]. }\end{array}$ \\
\hline Sscle14g100310 & - & - & 3.56 & 3.54 & Identified as a predicted effector by Derbyshire et al. 2017 [58]. \\
\hline Sscle01g005870 & - & - & 3.12 & 1.79 & $\begin{array}{l}\text { Putative Choline dehydrogenase or related flavoprotein (COG2303). Potentially involved in lipid } \\
\text { transport or metabolism. } 36 \% \text { identity to Sscle06g048860. }\end{array}$ \\
\hline Sscle08g066850 & - & - & 2.4 & 3.22 & $\begin{array}{l}\text { Contains chitin recognition domain (pfam00187) and GH18 domains containing both catalytically } \\
\text { active and inactive chitinase-like proteins (cd02872). }\end{array}$ \\
\hline Sscle14g098710 & - & 2.3 & - & - & . Contains a Common central domain of tyrosinase (pfam00264). \\
\hline Sscle08g068500 & - & - & 2.06 & - & Characterized as Ssitl and found to suppress JA signaling pathways \\
\hline Sscle01g000660 & 2.19 & - & - & - & Identified as a predicted effector by Derbyshire et al. 2017 [58]. \\
\hline Sscle04g036550 & 2.15 & - & - & - & Identified as a predicted effector by Derbyshire et al. 2017 [58]. \\
\hline Sscle01g004200 & - & - & 2.16 & - & Homologue of the predicted effector 5 protein discovered in Venturia inaequalis (Thakur et al. 2012). \\
\hline Sscle14g098880 & - & - & 1.94 & 2.99 & $\begin{array}{l}\text { Contains a ricin type beta-trefoil lectin domain (PF00652). This domain is common in the formation } \\
\text { of toxins, but is also known to be involved in signal transduction. }\end{array}$ \\
\hline Sscle04g038020 & - & - & 1.84 & 5.3 & $\begin{array}{l}\text { Contains a CyanoVirin-N Homology (CVNH) domain (pfam08881). Experimentally confirmed to be } \\
\text { essential for full virulence [106]. }\end{array}$ \\
\hline Sscle12g090380 & - & 1.84 & - & - & Identified as a predicted effector by Derbyshire et al. 2017 [58]. \\
\hline Sscle06g050280 & - & - & - & 5.04 & $\begin{array}{l}\text { Contains a CFEM domain (pfam05730) often associated with fungal pathogenesis. Up-regulation } \\
\text { was observed in B. napus infection, but not during the infection of several other host plants }[22,24] \text {. }\end{array}$ \\
\hline Sscle06g048860 & - & - & - & 3 & $\begin{array}{l}\text { Putative Choline dehydrogenase or related flavoprotein (COG2303). Potentially involved in lipid } \\
\text { transport or metabolism. 36\% identity to Sscle01g005870. }\end{array}$ \\
\hline Sscle08g063080 & - & - & - & 1.87 & Putative tripeptidyl peptidase shown to be up-regulated during infection of B. napus [24]. \\
\hline Sscle06g053560 & - & - & - & 2.5 & $\begin{array}{l}\text { Shares } 72 \% \text { identity with a cuticle-degrading serine protease found in Marssonina brunnea. Also } \\
\text { contains a peptidase inhibitor domain (pfam05922). }\end{array}$ \\
\hline Sscle02g012940 & - & - & - & 2.68 & Identified as a predicted effector by Derbyshire et al. 2017 [58]. \\
\hline Sscle01g008950 & - & - & - & 2.75 & $\begin{array}{l}\text { Identified as a predicted effector by Derbyshire et al. } 2017 \text { [58], but found to be strongly } \\
\text { up-regulated in developing apothecia. The relationship between the gene and virulence is } \\
\text { considered suspect [107]. }\end{array}$ \\
\hline
\end{tabular}

All putative secreted effectors identified as either up-regulated in-planta or differentially regulated over the course of infection. Justification for each gene's inclusion was given either through the description of previous characterization, relevant conserved domains/homology, or the study which predicted its candidacy.

chitinase activity [65]. Three genes putatively in this category (Sscle08g068200, Sscle07g062010, and Sscle08g066850) contain chitin binding domains and were up-regulated in at-least one timepoint, although whether these genes are acting purely as chitin binding proteins or as chitinases involved in fungal cell wall modification is unknown. Sscle08g068200 and Sscle07g062010 were up-regulated at all timepoints of infection, while Sscle08g066850 was upregulated only at 96 hpi (Table 4).

\section{Regulation of oxalic acid (OA) and reactive oxygen species (ROS)}

OA is a key virulence factor for $S$. sclerotiorum that is responsible for the upregulation of ROS within the host, and eventually the induction of programmed cell death (PCD) to the benefit of the pathogen [13, 66]. Thus, redox regulation during pathogenic development is likely to be critical to both the pathogen and the host.

The most well studied gene in OA biosynthesis is and oxaloacetate acetylhydrolase (Ssoah1; Sscle10g075560) 
which catalyzes the conversion of oxaloacetate to OA and carbon dioxide [67]. Previous studies in Phaseolus vulgaris and Brassica napus showed an up-regulation of Ssoah1 during infection [24, 25]. Surprisingly, this pattern was not conserved in the infection of soybean, and Ssoah1 showed no upregulation over the course of infection or when compared to culture (Tables S2 and S5). To confirm that Ssoah1 was being expressed during infection, an analysis of the average expression of each gene was conducted on all timepoints and reported as the average $\log _{2}$ of the read counts per million (Ave. Exp.) (Additional file 12: Table S12). This examination revealed that of the 9161 genes with an Ave. Exp. >1, Ssoah1 was the sixth highest (Ave. Exp. $=12.5$ ), and was excluded from the differential expression analysis because it was expressed at similar levels both in vitro and in planta (Additional file 13: Table S11). Given that media acidification is commonly used as a measure of OA biosynthesis within S. sclerotiorum, the expression of Ssoah1 in culture is not unexpected $[67,68]$. This analysis also highlighted two other genes with high average expression, the peroxiredoxin (Sscle06g048910) and the alcohol oxidase (Sscle03g024060), which were found to be both upregulated in planta and have likely roles in redox regulation (Additional file 12: Tables S12 and Additional file 6: Table S5).

Previous work in B. napus indicated that expression levels of oxalate decarboxylase (Sscle09g069850), an enzyme known to degrade OA, were up-regulated in concert with Ssoah1, likely due to a careful balance in the regulatory pathways of OA needed for successful infection [24]. A similar pattern was also seen during infection of soybean, given that both genes fell between $\operatorname{logFCs}$ of -1 and 1 over the course of infection and failed to qualify as a DEG, indicating constitutive expression.

NADPH oxidase (NOX) genes have been reported in a variety of species to be important ROS generators $[66,69$, 70]. The two NOX genes identified in S. sclerotiorum, Ssnox1 (Sscle05g048220) and Ssnox2 (Sscle12g087830), were both found to be consistently expressed over the course of infection and Ssnox 2 showed very similar expression patterns between infection and culture. Ssnox1, in contrast, showed significantly reduced expression in-planta as compared to culture $(\operatorname{logFC}=-2.47)$ (Additional file 6: Table S5).

While the induction of ROS in the plant is often the focus in this pathosystem, the ability of S. sclerotiorum to cope with ROS within the host is likely to be crucial. Along with the previously discussed peroxiredoxin, a $\mathrm{Cu} / \mathrm{Zn}$ superoxide dismutase (SOD) gene (Sssod1; Sscle03g025030) was shown to be important for virulence [71]. Sscle03g025030 was upregulated throughout our time course compared to culture (Additional file 14: Table S13), confirming its importance during infection.
Catalases and peroxidases can also serve as important ROS scavengers [72]. Four catalase enzymes (Sscle03g 026200, Sscle04g037170, Sscle05g047950, and Sscle15g 104430) were upregulated during infection, all showing highest expression at $96 \mathrm{hpi}$ and no induction at $24 \mathrm{hpi}$ (Additional file 14: Table S13), likely to coincide with peak ROS levels at the later stages of infection. The most upregulated catalase was the previously characterized Scat1 (Sscle04g037170), though its role in ROS detoxification is unclear [73]. Of the four peroxidase genes upregulated when compared to culture, two (Sscle03g 024750 and Sscle01g000730) show the greatest expression at $24 \mathrm{hpi}$ and two (Sscle07g058850 and Sscle06g053530) show greatest expression at $96 \mathrm{hpi}$ (Additional file 14: Table S13). Two additional peroxidases were not upregulated in comparison to culture, but did show either upregulation (Sscle09g070530; $\operatorname{logFC}=2.02$ ) or downregulation (Sscle01g007350; $\operatorname{logFC}$ $=-1.88$ ) when comparing early and late infection (Additional file 2: Table S2). Overall, detoxification of ROS is clearly a priority throughout the course of infection, but becomes particularly critical during the later stages of when OA induced ROS production induces broad scale programmed cell death in the host.

\section{Gene expression during S. sclerotiorum challenge of $\mathrm{R}$ and S Glycine max}

Transcriptomic analyses comparing $\mathrm{R}$ and $\mathrm{S}$ cultivars during infection with a pathogen have become an increasingly popular method of elucidating the mechanisms of plant resistance [30, 74]. The characterization of differentially regulated plant genes, proteins, and pathways can be pivotal in understanding novel mechanisms of resistance, but the effect of plant resistance on pathogen gene expression can be provide insight into fungal mechanisms deployed to counter this resistance as well.

DEGs were analyzed between the $\mathrm{R}$ and $\mathrm{S}$ infections for each timepoint of infection $(24,48$, and $96 \mathrm{hpi}$; $p$-value $<0.01 ; \operatorname{logFC}>1$ or $<-1) .99,62$, and 351 DEGs were generated through the comparison of $\mathrm{R}$ and $\mathrm{S}$ at 24, 48, and $96 \mathrm{hpi}$, respectively (Additional file 15: Table S14). These genes were classified into broader categories using the functional distribution tool within the FunCat database (FunCatDb) and S. sclerotiorum's annotated proteins (p3_r20263_ Scl_scler) [31] (Additional file 16: Table S15). An interesting observation is that of the DEG's at $24 \mathrm{hpi}$, 76.7\% (76/99) were up-regulated in $\mathrm{R}$ line infection, as opposed to only $23.4 \%(82 / 350)$ which were upregulated at $96 \mathrm{hpi}$. The fact that the $\mathrm{R}$ line largely suppressed SSR infection of its main stem (Fig. 1) suggests that this difference at $96 \mathrm{hpi}$ is likely due to a developmental delay of $S$. sclerotiorum. 
Despite the two infections being out-of-sync at $96 \mathrm{hpi}$, the functional distribution analysis of the DEGs at 24 hpi revealed potentially important strategic differences in gene expression between the two infections. Work to characterize the nature of the 91-145 line resistance noted an increased production of fungicidal organic acids [30], and we concurrently expected that the fungus in the $\mathrm{R}$ line would positively regulate genes related to detoxification in order to compensate. Although some regulatory shifts of these genes are observed, a similar number of genes related to detoxification/toxin transport were up- and downregulated in the resistant infection as compared to the susceptible (Fig. 7a). The most marked result of this analysis was the up-regulation of genes related secondary metabolism, particularly melanin. So far, only Scd1 (Sscle03g031470), Thr1 (Sscle03g 031480), and Sspks13 (Sscle03g031520) have been characterized as genes pivotal in melanin biosynthesis within S. sclerotiorum [75], although a tetrahydroxynaphthalene reductase (Sscle09g070740) also contains homology to known components of this pathway in other fungi. All four of these genes were upregulated in the $\mathrm{R}$ infection at 24 hpi with $\log \mathrm{FC}=\sim 2.0-2.4$. Given that one of the most important protective characteristics of melanin is its role as a hydrophobe within the fungal cell wall, the remaining DEGs at 24 HPI were analyzed to identify any other positively regulated structural or surface proteins serving a similar purpose.

Three putatively hydrophobic cell surface proteins were found to have been up-regulated from this list. The first gene, Sscle15g106410, contains a fungal hydrophobin domain (pfam06766) which is a small, moderately hydrophobic extracellular molecule that typically binds to the outside of fungal hyphae to mediate contact and communication between fungi and the environment. The second gene, Sscle12g091650, contains a Hydrophobic surface binding protein A (HsbA) domain (pfam12296) which was identified originally in Aspergillus oryzae as a surface protein important in both the adhesion to and degradation of hydrophobic surfaces [76]. The third gene, Sscle09g 070510, contains repeated fasciclin domains (pfam02469) which have been shown in Magnaporthe oryzae to be important in cell adhesion and binding to hydrophobic surfaces [77].

Prior work attempting to characterize the mechanism of SSR resistance within the $\mathrm{R}$ line indicated that it's antimicrobial activity likely targeted the biosynthesis/stability of ergosterol, a crucial component of fungal cell walls, through an unknown mechanism [66]. To determine if this activity affected the transcription of genes important in the biosynthesis of ergosterol, or if the fungus within the $\mathrm{R}$ line might be overproducing ergosterol in an attempt to offset these effects, several genes known to be important in this pathway were analyzed. Neither Erg28 (Sscle11g 086600), sterol 24-C-methyltransferase (Sscle07g 056400), nor CYP51 (Sscle02g013950), all of which have been characterized as important components of ergosterol synthesis, were found to be differentially regulated between the two lines at any timepoint [78-80].

Other genes of interest which were up-regulated in this timepoint comparison include a salicylate hydroxylase (Sscle05g045180) and a well characterized oxalate decarboxylase (Sscle09g069850). Previous studies have demonstrated S. sclerotiorum's capacity to degrade salicylate in-vitro and Sscle05g045180 was identified as an enzyme potentially responsible for this degradation [81]. Oxalate decarboxylase (Sscle09g 069850) is known to degrade OA, a pivotal virulence component during S. sclerotiorum infection. Although this activity appears counterintuitive given OA's importance in infection, the work characterizing this gene showed its induction was important in the formation of compound appressoria for host penetration [82]. This, along with the upregulation of the previously discussed hydrophobic surface proteins suggests that some expression differences at 24 hpi may be related to differences in S. sclerotiorum's penetration of the $\mathrm{R}$ and $\mathrm{S}$ lines.

\section{Discussion}

As a broad-host range, predominantly necrotrophic pathogen, S. sclerotiorum has a range of virulence factors, including CWDEs, detoxification enzymes, secreted effectors, and metabolites, that it employs to successfully infect a plethora of hosts [26]. Studies have singled out specific factors in the pathogenic development of $S$. sclerotiorum, largely in model plants [83]. However, only a few studies have focused on individual S. sclerotior$u m$-host interactions in crop plants. In this study, we provide a global overview of transcript regulation in $S$. sclerotiorum in association with soybean, and identify stage-dependent biological processes utilized by this fungus to successfully infect this important crop.

The temporal regulation of gene expression in culture, and in the early stages of infection compared to late infection highlighted the potential importance of transporters in the toxin efflux process during fungal infection. ATP-binding cassette $(\mathrm{ABC})$ transporters specifically have been characterized in a variety of fungi, including Magnaporthe oryzae [53] and Botrytis cinerea [54], as important factors in evading early plant defenses and establishing infection. In the case of $B$. cinerea, the $\mathrm{ABC}$ transporter BcAtrB was found to be important in fungal tolerance to the phytoalexin camalexin [54] . S. sclerotiorum's homolog of this gene (Sscle14g097690) was most induced during early infection. Further studies 
of this transporter proposed a likely synergistic relationship between $B c A \operatorname{tr} B$ and the detoxification enzyme $B c L C C 2$, which required early activity of $B c A t r B$ to reduce the accumulation of antifungal compounds and effectively degrade the target compounds in a $B c L C C 2$ dependent manner [84]. This suggests that in S. sclerotiorum-soybean interactions, $\mathrm{ABC}$ transporters potentially involved in toxin efflux are induced primarily early during infection (Additional file 10: Table S9), but a broader range of detoxification enzymes show either constitutive or late induction during infection (Table 3). A prime example of this is the GST Ssbgt1 (Sscle01g003110), which has been highlighted for its capacity to detoxify a range of phenolic phytoallexins from multiple plant species and was one of the most upregulated genes throughout infection (Table 3) [50]. We observed the strong induction of two other highly induced $\mathrm{ABC}$ transporters homologous to Bmr1 (Sscle02g016430) and Bmr3 (Sscle01g004040) from B. cinerea, which, along with $B c A \operatorname{tr} B$, have all been shown to be induced in the presence of phytoalexins (resveratrol and/or camalexin) [55]. This regulation indicates a potentially strong phytoalexin pressure on $S$. sclerotiorum during the early stages of infection of soybean.

Another group of genes whose induction appears primarily important during early infection are those related to nitrate/nitrite (Sscle02g013580, Sscle01g005230, and Sscle02g016460) metabolism. The relationship of this nitrate assimilation pathway in pathogenicity is still largely unexplored, but the strong induction of these genes may be due to the low nitrogen availability at the early stages of infection.

Necrotrophic fungi often rely on their large repertoire of hydrolytic CWDEs and S. sclerotiorum is no exception $[23,85]$. Over our time course analysis in soybean, $S$. sclerotiorum upregulated the expression of 178 putative CWDEs targeting a range of plant substrates (Table 2) and demonstrated distinct expression patterns for many of these enzymes. Comparative analysis across hosts revealed that among the 209 hydrolytic enzymes found to be upregulated during B. napus [24] infection, 55 transcripts, spanning putative arabinogalactan, callose, cellulose, lignin, lipid, mannan, protein, and starch degrading enzymes, were solely upregulated during infection of this host [24] (Additional file 17: Table S16). Conversely, 37 putative hydrolytic enzymes covering a similar range of substrates were only up-regulated during infection of soybean (Additional file 17: Table S16). This suggests that $S$. sclerotiorum deploys a specific repertoire of CWDEs depending on the host, highlighting the importance of studying this pathosystem in individual hosts.

Notable enzymes specifically deployed against soybean include a cutinase (Sscle02g013440) and polygalacturonase 2 (Sspg2; Sscle03g022740), both of which were highly induced in this study during early and late infection, respectively. Sspg2 expression was only noted during early infection of sunflower [20]. In soybean, however, Sspg2 is highly induced at all time points of infection in soybean and shows the largest differential expression in relation to culture of all PG's at 96 HPI. The late induction of many cutinase and cutin degrading enzymes seen in this study also contradicts previous assertions that these enzymes are primarily required during the initial penetration of the host $[21,24]$. Unlike many of the other CWDEs, all of the 28 identified genes coding for hemicellulose degrading enzymes were upregulated during this interaction (Table 2). Knowledge of this host-specific regulation of CWDEs is critical, both given their role as one of the most important virulence factors in necrotrophic fungal infection and in identifying the value of individual enzymes as targets in the control of SSR.

Serine proteases have been characterized as virulence determinants in a large number of phytopathogenic fungi, including Colletotrichum coccodes [86], Fusarium oxysporum [40], Colletotrichum acutatum [41], and Acremonium Strictum [87], and it has been noted that an elevated repertoire of subtilisins appears correlated with a necrotrophic lifestyle [42]. Seventeen serine proteases were identified and found to be upregulated in planta, and interestingly all showed the greatest induction at 24 hpi (Additional file 7: Table S6). Given that proteins involved in plant defense are a likely target of fungal proteolytic enzymes, this early induction may be due to an initial need to subvert the plants immune system which becomes less essential after the infection is established.

During infection, $B$. cinerea produces two major phytotoxic SMs, the sesquiterpene botrydial and the polyketide botcinic acid [88]. Although S. sclerotiorum lacks homologs of the genes to synthesize botrydial, it does possess homologs of the two B. cinerea genes, Bcboa6 (Sscle15g106510) and Bcboa9 (Sscle15g106480), that work in concert to synthesize botcinic acid [88]. Previous studies of S. sclerotiorum phytotoxin production, however, failed to identify botcinic acid [49], and transcriptomic analysis of S. sclerotiorum infection of $B$. napus only detected upregulation of Sscle15g106510 in planta [24]. Surprisingly, both Sscle15g106510 and Sscle15g106480 were up-regulated during infection of soybeans, with peak expression of both genes at 96 hpi. Bcboa6 and -9 belong to a larger SM gene cluster, which is largely conserved within the $S$. sclerotiorum genome, and appears to be upregulated during infection (Fig. 6). Our results provide the first indication that a phytotoxic analog of botcinic acid may play a role in S. sclerotiorum pathogenesis in soybean. Early characterization of botcinic acid identified the metabolite as a broad spectrum phytotoxin which induced chlorosis and necrosis in plant tissue [89], but the late induction of this 
SM cluster during soybean infection indicates that this is unlikely to be the primary role of this metabolite. More recent studies have proposed that botcinic acid may have antifungal properties as well [90]. This suggests that the induction of the botcinic acid SM cluster at 96 hpi may serve a dual role in plant colonization, both to induce PCD to kill the host and also to inhibit competitive colonization of the host by other saprophytic fungi.

Fifty-seven putative secreted effectors were observed to be upregulated and/or differentially regulated during infection, consisting of a mixture of previously characterized effectors, such as Ssv263 [15], Ssssvp1 [18], Ssnep2 [16], Ss-rhs1 [91], and Ssitl [17], and others which are highly induced, but whose functions are yet to be determined (Sscle07g055350, Sscle06g050280, Sscle05g045060, Sscle06g048920, Sscle06g 055310, Sscle11g080900). Although effectors are known to be secreted in "waves" corresponding to the various stages of infection, many of the most highly upregulated putative effectors were upregulated at all stages of infection in comparison to culture, indicating a more constitutive requirement during S. sclerotiorum infection (Table 4) [61, 62]. Despite this, some trends can still be deduced. All three of the effectors characterized as inducers of PCD (Ssssup1, Ssnep2, and Sscp1) showed the greatest expression at $96 \mathrm{hpi}$ (Table 4). This regulation is similar to that of the SM gene cluster putatively controlling botcinic acid biosynthesis, indicating that genes responsible for phytotoxicity and PCD induction in the host become increasingly active over the course of colonization. Alternatively, other putative effectors whose roles are more likely related to avoiding detection by the plant, such as the putative chitin binding Sscle08g068200 and Sscle07g062010, or undermining plant innate immunity, such as the chorismate mutase Sscle16g111080 [92], are more highly expressed during early infection (24-48 hpi) (Table 4). The recent discovery that the pathogen goes through a short biotrophic phase during early infiltration [93] supports a model whereby it prioritizes the subversion/ avoidance of plant resistance mechanisms early in infection and increases phytotoxic activity as the infection progresses, similar to prototypical hemibiotrophs [61]. This data also suggests that other, poorly characterized effectors with similar patterns of high expression in either early (Ssv263 [15], acp1 [39], Sscle15g106630, etc.) or late (Sscle07g055350, Sscle05g041050, Sscle04g040080, etc.) infection may be involved in these same processes.

Oxalic acid (OA) is a key virulence factor in the pathogenic development of S. sclerotiorum [8, 10, 12]. It is known to upregulate ROS within the host, leading to the cell suicide and the establishment of disease $[13,14,66]$. Thus, redox regulation and $\mathrm{OA}$ biogenesis are important factors to consider when studying a particular S. sclerotiorum-host interaction. Surprisingly the oxaloacetate acetylhydrolase gene (Ssoah1) primarily responsible for OA biogenesis was neither upregulated in comparison to culture nor between early and late infection. A previous study which noted a similar phenomenon posited that an alternate route of OA biosynthesis may be utilized during early infection [19], but high expression of Ssoah1 throughout infection and in culture indicates that the gene likely has an important role across all environments, thus precluding it from a differential expression analysis.

The upregulation of ROS by OA serves an important role in killing the host, but as ROS is broadly toxic to all life, S. sclerotiorum contains a number of ROS scavenging enzymes to maintain its own redox homeostasis during infection. In this study, four catalases (Scat1; Sscle04g037170, Sscle03g026200, Sscle05g047950, and Sscle15g104430), four peroxidases (Sscle03g024750, Sscle01g000730, Sscle07g058850, and Sscle06g053530), a superoxide dismutase (Sssod1; Sscle03g025030), and a peroxiredoxin (Sscle06g048910) were found to be upregulated in comparison to culture (Additional file 14: Table S13). These ROS scavenging enzymes showed unique temporal regulation over the course of infection, with the peroxiredoxin and two of the peroxidases (Sscle03g024750 and Sscle01g000730) being most upregulated at 24 hpi but all four of the catalases and the remaining two peroxidases demonstrating greatest expression at 96 hpi (Additional file 14: Table S13). Increased ROS scavenging activity during later infection corresponds with the likely accumulation of ROS required for the widespread cell death seen at 96 hpi. Early ROS scavenging activity may play a role in dampening the oxidative stress to the fungus as well, but the possible roles in fungal development cannot be overlooked as it's well established that ROS plays a pivotal role in intracellular signaling and cell-cell interactions [94].

Finally, an examination of S. sclerotiorum's transcriptome during infection of a resistant soybean line elucidated the reaction of the pathogen to a successful defense response by its host. During the resistant line infection, we detected increased expression of several secondary metabolism genes related to melanin biosynthesis as well as three putatively hydrophobic cell surface proteins (i.e. hydrophobins). While melanin biosynthesis is known to be induced by fungus in the presence of oxidative and/or osmotic stress [100], hydrophobins are often associated with fungal adhesion, infiltration, and suppression of host immune responses [102-105]. Previous studies on the hydrophobin-like gene, TasHyd1, from Trichoderma asperellum showed it to be vital in maintaining proper fungal wettability and in the adhesion of the fungus to the hosts roots [95]. Another function of hydrophobin-like genes was demonstrated in the human pathogen Aspergillus fumigatus, where it was shown that the protein served to mask the pathogen from recognition and the subsequent induction of innate immunity [96]. This function is of particular interest given that the same study 
demonstrated that melanin was an inducer of this immune response, providing a framework by which S. sclerotiorum may upregulate hydrophobins in concert with melanin to avoid triggering plant defenses. Although we cannot currently state whether the upregulation of these hydrophobic cell surface proteins is in response to chemical stress from the plant, increased difficulty in initial penetration, or an attempt to shield the pathogen from detection, it is clear that the fungus shows a distinct transcriptomic response to the resistant line at 24 hpi despite a lack of phenotypic differentiation until post- $48 \mathrm{hpi}$. The regulation of these hydrophobins and the increase in melanin biosynthesis may play a pivotal role in either fungal penetration or the early suppression of innate immunity, which would be an important requirement of $S$. sclerotiorum during its early biotrophic phase of infection [93].

\section{Conclusions}

Given the broad host range of S. sclerotiorum and the repertoire of virulence factors contained within its genome, transcriptomic analysis of individual S. sclerotiorum-host interactions is critical to future disease control efforts. In this study, gene expression of S. sclerotiorum was measured over the course of a compatible soybean infection. During early infection the pathogen prioritizes penetration and establishment by upregulating transporters involved in toxin efflux, nitrogen metabolism, and a variety of putative secreted effectors with likely roles in the suppression of plant immunity. As infection progresses the pathogen expresses a host-specific range of CWDEs and detoxification enzymes to release sugars from the plant cell walls and degrade antimicrobial compounds being produced as a response to colonization. By the later stages of infection, disease is well established and S. sclerotiorum appears to prioritize the transport of newly available carbohydrates, the induction of PCD in the host, and the formation of sclerotia as overwintering structures.

To study the response of $S$. sclerotiorum to a resistant (non-compatible) host, gene expression was compared to a susceptible interaction during early infection. Clear regulatory differences were identified in the production of melanin and hydrophobic surface proteins in the resistant interaction potentially indicating an attempt by the pathogen to either evade detection and/or defend against antifungal compounds. Knowledge of the mechanisms utilized by $S$. sclerotiorum to overcome either typical or novel mechanisms of plant resistance is invaluable in the pursuit of stable durable resistance to SSR and will be the focus of further research.

\section{Methods}

\section{Plant and fungal material}

For both the plant inoculations and culture controls, a wild type isolate of S. sclerotiorum strain 1980 was grown on potato dextrose agar (PDA) [10]. Strain 1980 was utilized as it is both a common laboratory strain of S. sclerotiorum and the genome sequenced strain used for downstream bioinformatic analysis in this study. Plant inoculations utilized agar plugs directly from this PDA culture, but culture controls were further cleaned and grown in glucose minimal (GMM) media prior to extraction. Fresh mycelia from PDA plates were scraped and then filtered through Miracloth (Darmstadt, Germany). Collected mycelia were washed $\left(40^{\circ} \mathrm{C}, 4000\right.$ $\mathrm{rpm}, 10 \mathrm{~min}$ ) twice with sterile autoclaved water and used to inoculate $100 \mathrm{ml}$ of GMM [97]. The GMM cultures were grown on a shaker for $48 \mathrm{~h}\left(150 \mathrm{rpm}, 25^{\circ} \mathrm{C}\right)$. Mycelia was collected by filtering through Miracloth (Darmstadt, Germany) and immediately frozen in liquid nitrogen prior to RNA extraction.

Two recombinants inbred lines of soybean (Glycine max), 91-145 and 91-44, were used in this study. Both lines were previously developed and evaluated as germplasm stock to increase quantitative resistance to SSR in soybean breeding programs, but are not commercially available [27]. Lines can be made available upon request to the corresponding author. Both the resistant 91-145 (R) and the susceptible 91-44 (S) lines were developed utilizing W04-1002 (P1), a SSR resistant parental line, and LN89-5717 (PI 5745542), a SSR-susceptible parental line demonstrating other desirable pathogen resistance traits [27]. Plants were supplemented with fertilizer (Miracle-Gro) every two weeks and maintained in the greenhouse or growth chamber at $24 \pm 2{ }^{\circ} \mathrm{C}$ with 16 -h light/8-h dark photoperiod cycle.

\section{Fungal inoculation}

Four week old soybean plants were infected with S. sclerotiorum by petiole inoculation as previously described [66], using a $1 \mathrm{ml}$ pipette tip agar plug of actively growing fungal hyphae. Plant tissue was sampled by cutting horizontally above and below $(1.5 \mathrm{~cm})$ the node of the inoculated petiole with a clean straight-edge razor. Tissue samples were then immediately frozen in liquid nitrogen prior to RNA extraction. The experimental design was completely randomized and consisted of three biological replicates for each of the treatments. For each of the experimental conditions, stem segments $(\sim 3$ $\mathrm{cm}$, first internode) from 2 different plants were pooled together to form one of three biological replicates.

\section{RNA extraction and library preparation}

Total RNA was extracted from soybean stem tissues and infecting S. sclerotiorum using a modified TRIzol ${ }^{\mathrm{m}}$ Reagent protocol (Invitrogen Corp., Carlsbad, CA, USA). Further, samples were cleaned using the RNeasy Plant Mini Kit (Qiagen, Hilden, Germany). RNA concentration and purity was determined by 
Nanodrop (Thermo Fisher Scientific, Wilmington, DE) and sample quality was assessed using an Agilent Bioanalyzer 2100 and an RNA 6000 Nano Kit (Agilent Technologies, Santa Clara, CA). Three biological replicates were generated per treatment.

Library preparation was performed at the University of Wisconsin - Madison Biotechnology Centre (Madison, WI, USA). Individually indexed libraries were prepared using the TruSeq RNA Sample Preparation v2 kit according to the manufacturer's instructions (Illumina, San Diego CA, USA). Library concentrations were quantified with the Qubit HS DNA kit (Thermo Fisher Scientific, Wilmington, DE). The size and quality of the libraries were evaluated with an Agilent Bioanalyzer 2100 and an Agilent DNA 1000 kit (Agilent Technologies, Santa Clara, CA) and the libraries were sequenced using Illumina HiSeq2500 (1X100bp) (Illumina, San Diego CA, USA).

\section{Quality check and sequence analysis}

Illumina raw read data quality was verified with FastQC (http://www.bioinformatics.babraham.ac.uk/ projects/fastqc/). The soybean and S. sclerotiorum genomes were collected from Phytozome v12.1 (https:// phytozome.jgi.doe.gov/pz/portal.html\#!bulk?or-

g=Org_Gmax) and the Broad institute (https:// www.broadinstitute.org/fungal-genome-initiative/sclerotinia-sclerotiorum-genome-project), respectively [23, 98]. Raw sequence reads were mapped to both genomes using the Subjunc aligner from Subread [99]. Alignments were compared to the gene annotation GFF files for both organisms (Soybean: Gmax_275_ Wm82.a2.v1.gene.gff3 [98], S. sclerotiorum: sclerotinia_sclerotiorum_2_transcripts.gtf [23]) and raw counts for each gene were generated using the feature Counts tool from Subread. The raw counts data were normalized with the trimmed mean of means (TMM) normalization method using edgeR package [100]. The normalized gene counts were transformed to $\log _{2}$ scale using the voom method from the R Limma package, then used to generate differential expression $\left(\log _{2} \mathrm{FC}\right)$ values [101, 102]. DEGs $\left(\log _{2} \mathrm{FC}>1\right.$ or $\left.<-1\right)$ were generated for S. sclerotiorum genes from the comparison of inoculated soybeans at different timepoints to the culture control (FDR $<0.05)$, between early $(24$ and $48 \mathrm{hpi})$ and late (96 hpi) infection (FDR $<0.05)$, and between the timepoints of resistant $(\mathrm{R})$ and susceptible (S) line infections ( $p$-value $<0.01)$. The different statistical threshold applied in the $\mathrm{R}$ vs $\mathrm{S}$ comparison ( $\mathrm{p}$-value $<0.01$ ) was utilized to account for a higher standard deviation in the $\mathrm{R}$ line replicates which precluded the usage of the more conservative FDR $<0.05$. To reduce the likelihood of false positives from low transcript genes, samples were filtered to remove DEGs in which all timepoints had average RPKM values $<1$. To utilize the most recent nomenclature in describing $S$. sclerotiorum genes, all gene loci were updated to the annotations assigned in the most recent full genome sequence of $S$. sclerotiorum [60] (Additional file 18: Table S17). Genes which were removed or combined in the most recent resequencing were removed from the analysis.

\section{Gene annotation and functional distribution characterization}

Putative annotations were assigned to all genes using the Blast2Go software [103]. Select genes were also analyzed for conserved domains, characterized homologues, and closely related pathogenic fungi using BlastP [104]. Functional categorization of DEGs was done using the FunCat database (FunCatDb) and S. sclerotiorum's annotated proteins (p3_r20263_Scl_scler). Functional distribution characterization was generated using the FunCat functional distribution tool, which applied a site-specific hypergeometric distribution to identify overrepresented functional categories (Bonferroni correction < 0.05) [31].

\section{RNA seq validation using reverse transcription quantitative PCR (RT-qPCR)}

Stems were harvested and immediately frozen in liquid nitrogen. RNA was isolated using the above-mentioned protocol and then treated with RNase-free DNaseI (NEB Inc., Ipswich, MA, USA). The RNA was reverse transcribed using the AMV First-Strand cDNA Synthesis Kit (NEB Inc., Ipswitch, MA) and oligo-dT primer according to the manufacturer's instructions. RT-qPCR was performed using a SensiFAST SYBR No ROX Kit (Bioline USA Inc., Taunton, MA, USA). Each reaction consisted of $5 \mu \mathrm{L}$ of SensiFAST SYBR No-ROX Mix, $1 \mu \mathrm{L}$ of 1:10-fold diluted template cDNAs, and $0.4 \mu \mathrm{L}$ of $10 \mu \mathrm{M}$ gene-specific forward and reverse primers in a final volume of $10 \mu \mathrm{L}$. Primers were either culled from the literature or designed using Primer3 software $[105,106]$ for the amplification of gene fragments that were approximately $100-250 \mathrm{bp}$ in length and with an annealing temperature of $60^{\circ} \mathrm{C}$ (Additional file 1: Table S1). The primer specificity was checked in silico against the NCBI database through the Primer-BLAST tool (http:// www.ncbi.nlm.nih.gov). RT-qPCR was performed on a CFX96 real-time PCR system (Bio-Rad, Hercules, CA). The run conditions were: $2 \mathrm{~min}$ of initial denaturation at $95^{\circ} \mathrm{C}$; $95^{\circ} \mathrm{C}$ for $5 \mathrm{~s}, 58^{\circ} \mathrm{C}$ for $10 \mathrm{~s}$, and $72^{\circ} \mathrm{C}$ for $20 \mathrm{~s}$ ( 40 cycles). The relative expression of genes was calculated using the $2-\Delta \Delta C$ t method [107] with the fungal $\beta$-tubulin gene (Sscle02g015170) used as an endogenous control. Three biological replicates quantified for each sample.

\section{Additional files}

Additional file 1: Table S1. Primers used in the validation of RNA sequencing data. All primers were either designed for this study or culled from literature. (XLSX 217 kb) 
Additional file 2: Table S2. All genes differentially expressed over the progression of $\mathrm{S}$ line infection. DEGs were generated through the comparison of average RPKM values between early infection (24 and 48 hpi) and late infection (96 hpi). FDR $<0.05$; Average RPKM $>1$; $\log F C \geq 1$ or $\leq-1$. (XLSX $111 \mathrm{~kb})$

Additional file 3: Table S3. Characterization and functional distribution of genes found to be differentially regulated over the progression of $S$ line infection. (A) LATE genes (B) EARLY genes. P-value, Bonferroni correction, and FDR are all given, but only samples with a Bonferroni correction $<0.05$ were considered in the analysis. (XLSX 66 kb)

Additional file 4: Figure S1. Graph detailing select categories of genes that were upregulated either EARLY (Orange) or LATE (Blue). Genes were categorized using based on Blast2GO annotation or characterized homologues. (PDF $21 \mathrm{~kb}$ )

Additional file 5: Table S4. All genes found to be differentially expressed over the course of infection (FDR<0.05) which were similarly identified within sclerotial exudates in the Liang et al 2010 study. (XLSX $12 \mathrm{~kb}$ )

Additional file 6: Table S5. All genes which were differentially expressed between three timepoints of the $S$ line infection and the culture control (C) (FDR<0.05; $\log F C>1$ or $\log F C<-1)$. "Positively Regulated?" denotes genes in which at least one timepoint had a logFC $>1$. (XLSX $249 \mathrm{~kb})$

Additional file 7: Table S6. All cell wall degrading and related hydrolytic enzymes upregulated at some timepoint of the $S$ line infection in comparison to the culture control (FDR<0.05; logFC>1). (XLSX 23 kb)

Additional file 8: Table S7. All putatively assigned secondary metabolite synthesis genes which were upregulated at some timepoint of the $\mathrm{S}$ line infection in comparison to the culture control $(\mathrm{FDR}<0.05$; $\log F C>1)$. (XLSX

$11 \mathrm{~kb})$

Additional file 9: : Table S8. All putatively assigned cytochrome P450 genes which were upregulated at some timepoint of the $S$ line infection in comparison to the culture control (FDR<0.05; logFC>1). (XLSX $11 \mathrm{~kb}$ )

Additional file 10: : Table S9. All putatively assigned transporter proteins which were upregulated at some timepoint of the $S$ line infection in comparison to the culture control (FDR<0.05; $\log F C>1)$. ( $X L S X$ $16 \mathrm{~kb})$

Additional file 11: Table S10. All putatively assigned transcription factors which were differentially regulated at some timepoint of the $S$ line infection in comparison to the culture control (FDR $<0.05$; log FC $>1$ or $\log F(<-1)$. "Positively Regulated?" denotes genes in which at least one timepoint had a logFC $>1$. (XLSX $14 \mathrm{~kb})$

Additional file 12: Table S12. Average expression analysis of all $\mathrm{S}$ line timepoints. "Ave. Exp." is calculated as the log2 of the average counts per million (CPM) for each sample. CPM is generated from RPKM values to normalize for sequencing depth among genes and replicates. (XLSX 1562 $\mathrm{kb})$

Additional file 13: Table S11. Raw RPKM value for $S \vee C$ timepoint comparison (A) 24 hpi (B) 48 hpi (C) 96 hpi (XLSX 4311 kb)

Additional file $\mathbf{1 4}$ Table S13. All putatively assigned ROS scavenging enzymes which were differentially regulated at some timepoint of the $S$ line infection in comparison to the culture control (FDR $<0.05$; $\log F C>1$ or $\log \mathrm{F}(<-1)$. "Positively Regulated?" denotes genes in which at least one timepoint had a $\log F C>1$. (XLSX $12 \mathrm{~kb})$

Additional file 15: Table S14. Timepoint comparison of $R$ and $S$ lines. LogFC $>1$ indicates higher expression in the R line infection. LogFC $<-1$ indicates higher expression in the $\mathrm{S}$ line infection. (XLSX $36 \mathrm{~kb}$ )

Additional file 16: Table S15. Characterization and functional distribution of genes found to be differentially regulated between the $R$ and $\mathrm{S}$ line infections. (A) DEGs at $24 \mathrm{hpi}$ (B) DEGs at 96 hpi. P-value, Bonferroni correction, and FDR are all given, but only samples with a Bonferroni correction < 0.05 were considered in the analysis. (XLSX 59 kb)
Additional file 17: Table S16. Comparison of S. sclerotiorum hydrolytic enzymes upregulated during infection of either soybean (This study) or $B$. napus [24]. (XLSX $36 \mathrm{~kb})$

Additional file 18: Table S17. Key describing the relationship between version one [23] and version two [60] gene loci annotations within the S. sclerotiorum genome. (XLSX $212 \mathrm{~kb})$

\section{Abbreviations}

ABC: ATP binding cassette; Ave. Exp: Average Expression BlastP: Protein BLAST; C: Culture control; CFEM: Common fungal extracellular membrane; CWD: Cell wall degrading; CYP450: Cytochrome P450; DBD: DNA-binding domain; DEG: Differentially expressed gene; EARLY: Genes showing upregulation early in infection; FDR: False discovery rate; GMM: Glucose minimal media; GST: Glutathione S-transferase; HPI: Hours post inoculation; LATE: Genes showing up-regulation late in infection; MFS: Major facilitator superfamily; NADPH: oxidase; NOX: logFC: $L_{2}$ fold change; NRPS: Nonribosomal peptide synthase; OA: Oxalic acid; PCD: Programmed cell death; PDA: Potato dextrose agar; PG: Polygalacturonase; PKS: Polyketide synthase; PTI: Pattern triggered immunity; R: Resistant line; RIL: Recombinant inbred lines; ROS: Reactive oxygen species; RPKM: Reads Per Kilobase of transcript, per Million mapped reads; S: Susceptible line; SM: Secondary metabolite; SOD: Superoxide dismutase; SSR: Sclerotinia stem rot; TF: Transcription factor; TM: Transmembrane; TMM: Trimmed mean of means

\section{Acknowledgements}

The authors thank ProteinCT (Madison, WI) for their assistance with the bioinformatic analysis. Next-generation sequencing was performed by the Biotechnology Center at UW-Madison.

\section{Funding}

This work was supported by the Wisconsin Soybean Marketing Board, the North Central Research Program, and the USDA-National Sclerotinia Initiative. Funds were utilized in the generation and analysis of data, as well as supporting the writing of the manuscript. None of the funding bodies played any part in the collection, analysis, or interpretation of the data or in the writing of the manuscript.

\section{Availability of data and materials}

The raw RNA-Seq data, RPKMs for each gene, and differential expression values discussed in this study are available in NCBI's Gene Expression Omnibus (GEO) and are accessible through GEO series accession number GSE121983. Soybean lines utilized in this study can be made available upon request to the corresponding author.

\section{Authors' contributions}

NMW, AR, SJ performed the experiments and analyzed data. CRG, DLS, and MK designed the project. NMW and MK wrote the manuscript. All authors read and approved the final manuscript.

Ethics approval and consent to participate

Not applicable.

\section{Consent for publication}

Not applicable.

\section{Competing interests}

The authors declare that they have no competing interests.

\section{Publisher's Note}

Springer Nature remains neutral with regard to jurisdictional claims in published maps and institutional affiliations.

Received: 22 August 2018 Accepted: 7 February 2019

Published online: 26 February 2019

\section{References}

1. Boland GJ, Hall R. Index of plant hosts of sclerotinia sclerotiorum. Can J Plant Pathol. 1994;16:93-108. 
2. Allen TW, Bradley CA, Sisson AJ, Coker CM, Dorrance AE, Esker PD, et al. Soybean Yield Loss Estimates Due to Diseases in the United States and Ontario, Canada, from 2010 to 2014. Plant Heal Prog. 2017;18:19-27. https://doi.org/10.1094/PHP-RS-16-0066.

3. Mueller DS, Hartman GL, Pedersen WL. Development of sclerotia and apothecia of Sclerotinia sclerotiorum from infected soybean seed and its control by fungicide seed treatment. Plant Dis. 1999;83:1113-5.

4. Adams P, Ayers WA. Ecology of Sclerotinia Species. Phytopathology. 1979; 69:896-8.

5. Wu BM, Subbarao KV. Effects of soil temperature, moisture, and burial depths on Carpogenic germination of Sclerotinia sclerotiorum and S. Minor. Phytopathology. 2008;98:1144-52. https://doi.org/10.1094/phyto-98-10-1144.

6. Boland GJ. Epidemiology of Sclerotinia stem rot of soybean in Ontario. Phytopathology. 1988;78:1241.

7. Vautard-Mey G, Cotton P, Fèvre M. Expression and compartmentation of the glucose repressor CRE1 from the phytopathogenic fungus Sclerotinia sclerotiorum. Eur J Biochem. 1999;266:252-9.

8. Rollins JA. The Sclerotinia sclerotiorum pac1 gene is required for sclerotial development and virulence. Mol Plant-Microbe Interact. 2003;16:785-95.

9. Kim HJ, Chen C, Kabbage M, Dickman MB. Identification and characterization of Sclerotinia sclerotiorum NADPH oxidases. Appl Environ Microbiol. 2011;77:7721-9. https://doi.org/10.1128/AEM.05472-11.

10. Godoy G, Steadman JR, Dickman MB, Dam R. Use of mutants to demonstrate the role of oxalic acid in pathogenicity of Sclerotinia sclerotiorum on Phaseolus vulgaris. Physiol Mol Plant Pathol. 1990;37: 179-91.

11. Davidson AL, Blahut-Beatty L, Itaya A, Zhang Y, Zheng S, Simmonds D. Histopathology of Sclerotinia sclerotiorum infection and oxalic acid function in susceptible and resistant soybean. Plant Pathol. 2016;65:878-87.

12. Magro $P$, Marciano $P$, Lenna P. Oxalic acid production and its role in pathogenesis of Sclerotinia sclerotiorum. FEMS Microbiol Lett. 1984;24:9-12

13. Kim KS, Min J, Dickman MB. Oxalic acid is an elicitor of plant programmed cell death during Sclerotinia sclerotiorum disease development. Mol PlantMicrobe Interact. 2008;21:605-12. https://doi.org/10.1094/MPMI-21-5-0605.

14. Williams B, Kabbage M, Kim HJ, Britt R, Dickman MB. Tipping the balance: Sclerotinia sclerotiorum secreted oxalic acid suppresses host defenses by manipulating the host redox environment. PLoS Pathog. 2011;7:e1002107.

15. Liang Y, Yajima W, Davis MR, Kav NNV, Strelkov SE. Disruption of a gene encoding a hypothetical secreted protein from Sclerotinia sclerotiorum reduces its virulence on canola (Brassica napus). Can J Plant Pathol. 2013;35:46-55.

16. Dallal Bashi Z, Hegedus DD, Buchwaldt L, Rimmer SR, Borhan MH. Expression and regulation of Sclerotinia sclerotiorum necrosis and ethyleneinducing peptides (NEPs). Mol Plant Pathol. 2010;11:43-53.

17. Zhu W, Wei W, Fu Y, Cheng J, Xie J, Li G, et al. A secretory protein of necrotrophic fungus Sclerotinia sclerotiorum that suppresses host resistance. PLoS One. 2013:8:e53901.

18. Lyu X, Shen C, Fu Y, Xie J, Jiang D, Li G, et al. A small secreted virulencerelated protein is essential for the necrotrophic interactions of Sclerotinia sclerotiorum with its host plants. PLoS Pathog. 2016;12:1-28.

19. Li R, Rimmer R, Buchwaldt L, Sharpe AG, Séguin-Swartz G, Hegedus DD. Interaction of Sclerotinia sclerotiorum with Brassica napus: cloning and characterization of endo- and exo-polygalacturonases expressed during saprophytic and parasitic modes. Fungal Genet Biol. 2004;41:754-65.

20. Cotton P, Rascle C, Fevre M. Characterization of PG2, an early endoPG produced by Sclerotinia sclerotiorum, expressed in yeast. FEMS Microbiol Lett. 2002;213:239-44.

21. Bashi ZD, Rimmer SR, Khachatourians GG, Hegedus DD. Factors governing the regulation of Sclerotinia sclerotiorum cutinase a and polygalacturonase 1 during different stages of infection. Can J Microbiol. 2012;58:605-16. https:// doi.org/10.1139/w2012-031.

22. Guyon K, Balagué C, Roby D, Raffaele S. Secretome analysis reveals effector candidates associated with broad host range necrotrophy in the fungal plant pathogen Sclerotinia sclerotiorum Secretome analysis reveals effector candidates associated with broad host range necrotrophy in the fungal pla. BMC Genomics. 2014;15:336.

23. Amselem J, Cuomo CA, van Kan JAL, Viaud M, Benito EP, Couloux A, et al. Genomic analysis of the necrotrophic fungal pathogens sclerotinia sclerotiorum and botrytis cinerea. PLoS Genet. 2011;7:e1002230.

24. Seifbarghi S, Borhan MH, Wei Y, Coutu C, Robinson SJ, Hegedus DD. Changes in the Sclerotinia sclerotiorum transcriptome during infection of Brassica napus. BMC Genomics. 2017;18:1-37.
25. Oliveira MB, de Andrade RV, Grossi-de-Sá MF, Petrofeza S. Analysis of genes that are differentially expressed during the Sclerotinia sclerotiorumPhaseolus vulgaris interaction. Front Microbiol. 2015;6:1-14.

26. Bolton MD, Thomma BPHJ, Nelson BD. Sclerotinia sclerotiorum (lib.) de Bary: biology and molecular traits of a cosmopolitan pathogen. Mol Plant Pathol. 2006;7:1-16.

27. McCaghey M, Willbur J, Ranjan A, Grau CR, Chapman S, Diers B, et al. Development and Evaluation of Glycine max Germplasm Lines with Quantitative Resistance to Sclerotinia sclerotiorum. Front Plant Sci. 2017;8:1-13. https://doi.org/ 10.3389/fpls.2017.01495.

28. Kim HS, Diers BW. Inheritance of partial resistance to sclerotinia stem rot in soybean. Crop Sci. 2000;40:55-61.

29. Willbur JF, Ding S, Marks ME, Lucas H, Grau CR, Groves CL, et al. Comprehensive Sclerotinia stem rot screening of soybean germplasm requires multiple isolates of Sclerotinia sclerotiorum. Plant Dis. 2017;101:34453. https://doi.org/10.1094/PDIS-07-16-1055-RE.

30. Ranjan A, Westrick N, Jain S, Piotrowski JS, Ranjan M, Kessens R, et al. Resistance against Sclerotinia sclerotiorum in soybean involves a reprogramming of the phenylpropanoid pathway and upregulation of antifungal activity targeting ergosterol biosynthesis. Plant Biotechnol J. 2019;17: 1-15. https://doi.org/10.1111/pbi.13082

31. Ruepp A, Zollner A, Maier D, Albermann K, Hani J, Mokrejs M, et al. The FunCat, a functional annotation scheme for systematic classification of proteins from whole genomes. Nucleic Acids Res. 2004;32:5539-45.

32. VanEtten $\mathrm{H}$, Temporini $\mathrm{E}$, Wasmann C. Phytoalexin (and phytoanticipin) tolerance as a virulence trait: why is it not required by all pathogens? Physiol Mol Plant Pathol. 2001;59:83-93.

33. Li M, Rollins JA. The development-specific ssp1 and ssp2 genes of Sclerotinia sclerotiorum encode lectins with distinct yet compensatory regulation. Fungal Genet Biol. 2010;47:531-8. https://doi.org/10.1016/j.fgb. 2010.03.008

34. Van Damme EJM, Nakamura-Tsuruta S, Hirabayashi J, Rougé P, Peumans WJ. The Sclerotinia sclerotiorum agglutinin represents a novel family of fungal lectins remotely related to the Clostridium botulinum non-toxin haemagglutinin HA33/a. Glycoconj J. 2007;24:143-56.

35. Liang Y, Strelkov SE, Kav NNV. The proteome of liquid sclerotial exudates from sclerotinia sclerotiorum. J Proteome Res. 2010;9:3290-8.

36. Shieh MT, Brown RL, Whitehead MP, Cary JW, Cotty PJ, Cleveland TE, et al. Molecular genetic evidence for the involvement of a specific polygalacturonase, P2c, in the invasion and spread of Aspergillus flavus in cotton bolls. Appl Environ Microbiol. 1997;63:3548-52.

37. ten Have A, Mulder W, Visser J, van Kan JAL. The Endopolygalacturonase gene Bcpg1 is required for full virulence of Botrytis cinerea. Mol Plant-Microbe Interact. 1998;11:1009-16. https://doi.org/10.1094/MPMI.1998.11.10.1009.

38. Franceschetti M, Maqbool A, Jiménez-Dalmaroni MJ, Pennington HG, Kamoun S, Banfield MJ. Effectors of filamentous plant pathogens: commonalities amid diversity. Microbiol Mol Biol Rev. 2017;81:e00066-16. https://doi.org/10.1128/MMBR.00066-16.

39. Poussereau N, Creton S, Billon-Grand G, Rascle C, Fevre M. Regulation of acp1, encoding a non-aspartyl acid protease expressed during pathogenesis of Sclerotinia sclerotiorum. Microbiology. 2001;147:717-26.

40. Jashni MK, Dols IHM, lida Y, Boeren S, Beenen HG, Mehrabi R, et al. Synergistic action of a metalloprotease and a serine protease from Fusarium oxysporum f. Sp. lycopersici cleaves chitin-binding tomato Chitinases, reduces their antifungal activity, and enhances fungal virulence. Mol Plant-Microbe Interact. 2015;28:996-1008. https://doi.org/ 10.1094/MPMI-04-15-0074-R

41. Gregori R, Guidarelli M, Mari M. Preliminary studies on partial reduction of Colletotrichum acutatum infection by proteinase inhibitors extracted from apple skin. Physiol Mol Plant Pathol. 2010;74:303-8. https://doi.org/10.1016/j. pmpp.2010.04.006.

42. Muszewska A, Stepniewska-Dziubinska MM, Steczkiewicz K, Pawlowska J, Dziedzic A, Ginalski K. Fungal lifestyle reflected in serine protease repertoire. Sci Rep. 2017;7:1-12. https://doi.org/10.1038/s41598-017-09644-w.

43. De Assis Tacco BAC, Parente JA, Barbosa MS, Báo SN, De Souza GT, Pereira $M$, et al. Characterization of a secreted aspartyl protease of the fungal pathogen Paracoccidioides brasiliensis. Med Mycol. 2009;47:845-54.

44. Rementeria A, López-Molina N, Ludwig A, Vivanco AB, Bikandi J, Pontón J, et al. Genes and molecules involved in Aspergillus fumigatus virulence. Rev Iberoam Micol. 2005;22:1-23. 
45. Fillinger $S$, Elad Y. Botrytis - the fungus, the pathogen and its Management in Agricultural Systems; 2016. https://doi.org/10.1007/978-3-319-23371-0.

46. Howlett BJ. Secondary metabolite toxins and nutrition of plant pathogenic fungi. Curr Opin Plant Biol. 2006;9:371-5.

47. Diaz GJ, Murcia HW, Cepeda SM. Cytochrome p450 enzymes involved in the metabolism of aflatoxin b1 in chickens and quail. Poult Sci. 2010;89:2461-9.

48. Črešnar B, Petrič Š. Cytochrome P450 enzymes in the fungal kingdom. Biochim Biophys Acta. 1814;2011:29-35.

49. Pedras MSC, Ahiahonu PWK. Phytotoxin production and phytoalexin elicitation by the phytopathogenic fungus Sclerotinia sclerotiorum. J Chem Ecol. 2004;30:2163-79.

50. Sexton AC, Minic Z, Cozijnsen AJ, Pedras MSC, Howlett BJ. Cloning, purification and characterisation of brassinin glucosyltransferase, a phytoalexin-detoxifying enzyme from the plant pathogen Sclerotinia sclerotiorum. Fungal Genet Biol. 2009;46:201-9. https://doi.org/10.1016/j.fgb.2008.10.014.

51. Shraddha SR, Sehgal S, Kamthania M, Kumar A. Phytases: Microbial sources, production, purification, and potential biotechnological applications. Enzyme Res. 2011.

52. Morel M, Ngadin AA, Droux M, Jacquot JP, Gelhaye E. The fungal glutathione S-transferase system. Evidence of new classes in the wooddegrading basidiomycete Phanerochaete chrysosporium. Cell Mol Life Sci. 2009;66:3711-25.

53. Urban M, Bhargava T, Hamer JE. An ATP-driven efflux pump is a novel pathogenicity factor in rice blast disease. EMBO J. 1999;18:512-21.

54. Stefanato FL, Abou-Mansour E, Buchala A, Kretschmer M, Mosbach A, Hahn $M$, et al. The $A B C$ transporter BcatrB from Botrytis cinerea exports camalexin and is a virulence factor on Arabidopsis thaliana. Plant J. 2009;58:499-510.

55. Makizumi Y, Takedai S, Matsuzaki S, Nakaune R, Hamamoto H, Akutsu KHT. Cloning and selective toxicant-induced expression of BMR1 and BMR3, novel ABC transporter genes in Botrytis cinerea. J Gen Plant Pathol. 2002;68:338-41.

56. Schoonbeek H, Del Sorbo G, De Waard MA. The ABC transporter BcatrB affects the sensitivity of Botrytis cinerea to the phytoalexin resveratrol and the fungicide fenpiclonil. Mol Plant-Microbe Interact. 2001;14:562-71. https://doi.org/10.1094/MPMI.2001.14.4.562.

57. Fan H, Yu G, Liu Y, Zhang X, Liu J, Zhang Y, et al. An atypical forkheadcontaining transcription factor $\mathrm{SsFKH1}$ is involved in sclerotial formation and is essential for pathogenicity in Sclerotinia sclerotiorum. Mol Plant Pathol. 2017;18:963-75.

58. Wang L, Liu Y, Liu J, Zhang Y, Zhang X, Pan H. The Sclerotinia sclerotiorum FoxE2 gene is required for apothecial development. Phytopathology. 2016; 106:484-90. https://doi.org/10.1094/PHYTO-08-15-0181-R.

59. Win J, Krasileva KV, Kamoun S, Shirasu K, Staskawicz BJ, Banfield MJ. Sequence divergent RXLR effectors share a structural fold conserved across plant pathogenic oomycete species. PLoS Pathog. 2012;8:8-11.

60. Derbyshire M, Denton-Giles M, Hegedus D, Seifbarghi S, Rollins J, Van Kan J, et al. The complete genome sequence of the phytopathogenic fungus Sclerotinia sclerotiorum reveals insights into the genome architecture of broad host range pathogens. Genome Biol Evol. 2017:9:593-618.

61. O'Connell RJ, Thon MR, Hacquard S, Amyotte SG, Kleemann J, Torres MF, et al. Lifestyle transitions in plant pathogenic Colletotrichum fungi deciphered by genome and transcriptome analyses. Nat Genet. 2012;44:1060-5. https:// doi.org/10.1038/ng.2372.

62. Mirzadi Gohari A, Ware SB, Wittenberg AHJ, Mehrabi R, Ben M'Barek S, Verstappen ECP, et al. Effector discovery in the fungal wheat pathogen Zymoseptoria tritici. Mol Plant Pathol. 2015;16:931-45.

63. Giraldo MC, Valent B. Filamentous plant pathogen effectors in action. Nat Rev Microbiol. 2013;11:800-14. https://doi.org/10.1038/nrmicro3119.

64. Yang G, Tang L, Gong Y, Xie J, Fu Y, Jiang D, et al. A cerato-platanin protein SsCP1 targets plant PR1 and contributes to virulence of Sclerotinia sclerotiorum. New Phytol. 2018;217:739-55.

65. Mach J. N-glycosylation of a chitin binding effector allows a fungal pathogen to evade the plant immune response. Plant Cell. 2014;26:2009-17. https://doi.org/10.1105/tpc.114.125120.

66. Ranjan A, Jayaraman D, Grau C, Hill JH, Whitham SA, Ané JM, et al. The pathogenic development of Sclerotinia sclerotiorum in soybean requires specific host NADPH oxidases. Mol Plant Pathol. 2018;19:700-14.

67. Liang X, Liberti D, Li M, Kim YT, Hutchens A, Wilson R, et al. Oxaloacetate acetylhydrolase gene mutants of Sclerotinia sclerotiorum do not accumulate oxalic acid, but do produce limited lesions on host plants. Mol Plant Pathol. 2015;16:559-71.
68. Xu L, Xiang M, White $D, C$ hen $W$. pH dependency of sclerotial development and pathogenicity revealed by using genetically defined oxalate-minus mutants of Sclerotinia sclerotiorum. Environ Microbiol. 2015;17:2896-909.

69. Meitzler JL, Antony S, Wu Y, Juhasz A, Liu H, Jiang G, et al. NADPH oxidases: a perspective on reactive oxygen species production in tumor biology. Antioxid Redox Signal. 2014;20:2873-89. https://doi.org/10.1089/ars.2013.5603.

70. Takemoto D, Tanaka A, Scott B. NADPH oxidases in fungi: diverse roles of reactive oxygen species in fungal cellular differentiation. Fungal Genet Biol. 2007:44:1065-76.

71. Xu L, Chen W. Random T-DNA mutagenesis identifies a cu/Zn superoxide dismutase gene as a virulence factor of Sclerotinia sclerotiorum. Mol Plant-Microbe Interact. 2013;26:431-41. https://doi.org/ 10.1094/MPMI-07-12-0177-R.

72. Schaffer WM, Bronnikova TV. Peroxidase-ROS interactions. Nonlinear Dyn. 2012;68:413-30

73. Yarden O, Veluchamy S, Dickman MB, Kabbage M. Sclerotinia sclerotiorum catalase SCAT1 affects oxidative stress tolerance, regulates ergosterol levels and controls pathogenic development. Physiol Mol Plant Pathol. 2014;85: 34-41. https://doi.org/10.1016/j.pmpp.2013.12.001.

74. Wu J, Zhao Q, Yang Q, Liu H, Li Q, Yi X, et al. Comparative transcriptomic analysis uncovers the complex genetic network for resistance to Sclerotinia sclerotiorum in Brassica napus. Sci Rep. 2016;6:1-16. https://doi.org/10.1038/ srep19007.

75. Liang Y, Xiong W, Steinkellner S, Feng J. Deficiency of the melanin biosynthesis genes SCD1 and THR1 affects sclerotial development and vegetative growth, but not pathogenicity, in Sclerotinia sclerotiorum. Mol Plant Pathol. 2018;19:1444-53.

76. Ohtaki S, Maeda H, Takahashi T, Hasegawa F, Gomi K, Abe K, et al. Novel Hydrophobic Surface Binding Protein, HsbA, Produced by Aspergillus oryzae Novel Hydrophobic Surface Binding Protein, HsbA, Produced by Aspergillus oryzae. Appl Environ Microbiol. 2006;72:2407-13. https://doi.org/ 10.1128/AEM.72.4.2407.

77. Liu T, Chen G, Min H, Lin F. MoFLP1, encoding a novel fungal fasciclin-like protein, is involved in conidiation and pathogenicity in Magnaporthe oryzae. J Zhejiang Univ Sci B. 2009;10:434-44. https://doi.org/10.1631/jzus. B0920017.

78. Mo C, Bard M. Erg28p is a key protein in the yeast sterol biosynthetic enzyme complex. J Lipid Res. 2005;46:1991-8. https://doi.org/10.1194/jlr. M500153-JLR200.

79. Nes WD, Zhou W, Ganapathy K, Liu JL, Vatsyayan R, Chamala S, et al. Sterol 24-C-methyltransferase: an enzymatic target for the disruption of ergosterol biosynthesis and homeostasis in Cryptococcus neoformans. Arch Biochem Biophys. 2009;481:210-8. https://doi.org/10.1016/j.abb.2008.11.003.

80. Koch A, Kumar N, Weber L, Keller H, Imani J, Kogel K-H. Host-induced gene silencing of cytochrome P450 lanosterol C14 -demethylase-encoding genes confers strong resistance to Fusarium species. Proc Natl Acad Sci. 2013;110: 19324-9. https://doi.org/10.1073/pnas.1306373110.

81. Penn CD, Daniel SL. Salicylate degradation by the fungal plant pathogen sclerotinia sclerotiorum. Curr Microbiol. 2013;67:218-25.

82. Liang X, Moomaw EW, Rollins JA. Fungal oxalate decarboxylase activity contributes to Sclerotinia sclerotiorum early infection by affecting both compound appressoria development and function. Mol Plant Pathol. 2015; 16:825-36.

83. Mccaghey M, Willbur J, Smith DL, Kabbage M. The complexity of the Sclerotinia sclerotiorum pathosystem in soybean: virulence factors, resistance mechanisms, and their exploitation to control Sclerotinia stem rot; 2018.

84. Schouten A, Maksimova O, Cuesta-Arenas Y, Van Den Berg G, Raaijmakers $J M$. Involvement of the $A B C$ transporter BCAtrB and the laccase BCLCC2 in defence of Botrytis cinerea against the broad-spectrum antibiotic 2,4diacetylphloroglucinol. Environ Microbiol. 2008;10:1145-57.

85. Kubicek CP, Starr TL, Glass NL. Plant Cell Wall-degrading enzymes and their secretion in plant-pathogenic Fungi. Annu Rev Phytopathol. 2014;52:427-51. https://doi.org/10.1146/annurev-phyto-102313-045831.

86. Redman RS, Rodriguez RJ. Characterization and isolation of an extracellular serine protease from the tomato pathogen Colletotrichum coccodes, and it's role in pathogenicity. Mycol Res. 2002;106:1427-34.

87. Chalfoun NR, Grellet-Bournonville CF, Martínez-Zamora MG, Díaz-Perales A, Castagnaro AP, Díaz-Ricci JC. Purification and characterization of AsES protein: a subtilisin secreted by acremonium strictum is a novel plant defense elicitor. J Biol Chem. 2013;288:14098-113. 
88. Dalmais B, Schumacher J, Moraga J, Le Pêcheur P, Tudzynski B, Collado IG, et al. The Botrytis cinerea phytotoxin botcinic acid requires two polyketide synthases for production and has a redundant role in virulence with botrydial. Mol Plant Pathol. 2011:12:564-79.

89. Cutler H, Parker S, Ross S. Crumley F and SP. Homobotcinolide: a biologically active natural homolog of Botcinolide from Botrytis cinerea. Biosci Biotechnol Biochem. 1996;60:656-8. https://doi.org/10.1248/cpb.37.3229.

90. Sakuno E, Tani H, Nakajima H. 2- epi-Botcinin a and 3- O-Acetylbotcineric acid from Botrytis cinerea. Biosci Biotechnol Biochem. 2007;71:2592-5. https://doi.org/10.1271/bbb.70334.

91. Yu Y, Xiao J, Zhu W, Yang Y, Mei J, Bi C, et al. Ss-Rhs1, a secretory Rhs repeat-containing protein, is required for the virulence of Sclerotinia sclerotiorum. Mol Plant Pathol. 2017;18:1052-61.

92. Nováková M, Šašek V, Dobrev PI, Valentová O, Burketová L. Plant hormones in defense response of Brassica napus to Sclerotinia sclerotiorum reassessing the role of salicylic acid in the interaction with a necrotroph. Plant Physiol Biochem. 2014;80:308-17.

93. Kabbage M, Yarden O, Dickman MB. Pathogenic attributes of Sclerotinia sclerotiorum: switching from a biotrophic to necrotrophic lifestyle. Plant Sci. 2015;233:53-60. https://doi.org/10.1016/j.plantsci.2014.12.018.

94. Tudzynski P, Heller J, Siegmund U. Reactive oxygen species generation in fungal development and pathogenesis. Curr Opin Microbiol. 2012;15:653-9. https://doi.org/10.1016/j.mib.2012.10.002.

95. Viterbo A, Chet I. TasHyd1, a new hydrophobin gene from the biocontrol agent Trichoderma asperellum, is involved in plant root colonization. Mol Plant Pathol. 2006:7:249-58.

96. Rambach G, Blum G, Latge JP, Fontaine T, Heinekamp T, Hagleitner M, et al. Identification of Aspergillus fumigatus surface components that mediate interaction of conidia and hyphae with human platelets. J Infect Dis. 2015; 212:1140-9.

97. Shimizu K, Keller NP. Genetic involvement of a cAMP-dependent protein kinase in a $\mathrm{G}$ protein signaling pathway regulating morphological and chemical transitions in Aspergillus nidulans. Genetics. 2001;157:591-600 http://www.pubmedcentral.nih.gov/articlerender.fcgi?artid=1461531\&tool= pmcentrez\&rendertype $=$ abstract.

98. Schmutz J, Cannon SB, Schlueter J, Ma J, Mitros T, Nelson W, et al. Genome sequence of the palaeopolyploid soybean. Nature. 2010;463:178-83. https:// doi.org/10.1038/nature08670.

99. Liao Y, Smyth GK, Shi W. The subread aligner: fast, accurate and scalable read mapping by seed-and-vote. Nucleic Acids Res. 2013;41:e108.

100. Robinson MD, Oshlack A. A scaling normalization method for differential expression analysis of RNA-seq data. Genome Biol. 2010;11:R25.

101. Law CW, Chen Y, Shi W, Smyth GK. Voom: precision weights unlock linear model analysis tools for RNA-seq read counts. Genome Biol. 2014;15:1-17.

102. Ritchie ME, Phipson B, Wu D, Hu Y, Law CW, Shi W, et al. Limma powers differential expression analyses for RNA-sequencing and microarray studies. Nucleic Acids Res. 2015;43:e47.

103. Conesa A, Götz S, García-Gómez JM, Terol J, Talón M, Robles M. Blast2GO: a universal tool for annotation, visualization and analysis in functional genomics research. Bioinformatics. 2005;21:3674-6.

104. Altschul SF, Madden TL, Schäffer AA, Zhang J, Zhang Z, Miller W, et al. Gapped BLAST and PSI-BLAST: a new generation of protein database search programs. Nucleic Acids Res. 1997;25:3389-402.

105. Untergasser A, Cutcutache I, Koressaar T, Ye J, Faircloth BC, Remm M, et al. Primer3-new capabilities and interfaces. Nucleic Acids Res. 2012;40:1-12.

106. Koressaar T, Remm M. Enhancements and modifications of primer design program Primer3. Bioinformatics. 2007;23:1289-91.

107. Livak K, Schmittgen TD. Analysis of relative gene expression data using real-time quantitative $P C R$ and the 2- $\Delta \Delta C T$ method. Methods. 2001:25: $402-8$.

Ready to submit your research? Choose BMC and benefit from:

- fast, convenient online submission

- thorough peer review by experienced researchers in your field

- rapid publication on acceptance

- support for research data, including large and complex data types

- gold Open Access which fosters wider collaboration and increased citations

- maximum visibility for your research: over $100 \mathrm{M}$ website views per year

At $\mathrm{BMC}$, research is always in progress.

Learn more biomedcentral.com/submissions 